\title{
Impact of auditory and visual distractors upon learning a manual assembly task in older workers
}

Diana J. Schwerha

West Virginia University

Follow this and additional works at: https://researchrepository.wvu.edu/etd

\section{Recommended Citation}

Schwerha, Diana J., "Impact of auditory and visual distractors upon learning a manual assembly task in older workers" (2004). Graduate Theses, Dissertations, and Problem Reports. 2574.

https://researchrepository.wvu.edu/etd/2574

This Dissertation is protected by copyright and/or related rights. It has been brought to you by the The Research Repository @ WVU with permission from the rights-holder(s). You are free to use this Dissertation in any way that is permitted by the copyright and related rights legislation that applies to your use. For other uses you must obtain permission from the rights-holder(s) directly, unless additional rights are indicated by a Creative Commons license in the record and/ or on the work itself. This Dissertation has been accepted for inclusion in WVU Graduate Theses, Dissertations, and Problem Reports collection by an authorized administrator of The Research Repository @ WVU.

For more information, please contact researchrepository@mail.wvu.edu. 
Impact of Auditory and Visual Distractors Upon Learning a Manual Assembly Task in Older Workers

Diana J. Schwerha

\author{
Dissertation submitted to the \\ College of Engineering and Mineral Resources \\ at West Virginia University \\ in partial fulfillment of the requirements \\ for the degree of \\ Doctor of Philosophy \\ in \\ Industrial and Management Systems Engineering
}
Steven Wiker, Ph.D., C.P.E., Chair
Majid Jaraiedi, Ph.D.
Ralph Plummer, Ph.D.
Gary Winn, Ph.D.
Julie Hicks Patrick, Ph.D.
Dianne L. McMullin, Ph.D., C.P.E.

Department of Industrial and Management Systems Engineering

\author{
Morgantown, West Virginia
}

2004

Keywords: Aging, Distraction, Field Dependence, Spatial Reasoning, Manual Assembly, Motor Performance, Memory, Perception

Copyright 2004 Diana J. Schwerha 


\begin{abstract}
Impact of Auditory and Visual Distractors Upon Learning a Manual Assembly Task in Older Workers
\end{abstract}

Diana J. Schwerha

This research investigated the impact of age upon learning a manual assembly task in the presence of visual and auditory distractors in males and females ranging in age between 18 and 65 years. Four phases of learning were studied: the number of initial error trials, the number of times the instructional video was watched, the total number of trials needed to complete the experiment, and trial time. Age was only found to be a significant factor for the total number of trials; subjects aged $51-65$ took $31 \%$ more trials than the younger subjects. Additionally, older subjects who were exposed to the dual distractor condition took $56 \%$ more trials than younger subjects who were not exposed to distractors. No main distractor effects were found, but the age $\mathrm{x}$ visual distractor was found to be significant for trial time. Older subjects with the visual distractor had $25 \%$ slower times than their younger counterparts in the no distractor condition. Auditory distractors were never found to be problematic for any age group or for any phase of learning. However, differences in spatial reasoning significantly mediated age effects and indicate that selection of individuals with significant spatial reasoning skills outweigh detrimental effects of aging when individuals are confronted with learning new psychomotor tasks, such as those studied, in the presence of distractions. 


\section{DEDICATION}

This manuscript is being dedicated to my patient, loving, and supportive husband, William F. Schneider. 


\section{ACKNOWLEDGMENTS}

First, I want to give thanks to our awesome God for giving me the strength to get through this project. I would like to express my sincere thanks to my advisors and chairmen of my committee, Dr. Majid Jaraiedi and Dr. Steven Wiker for their wit, wisdom, and constant support throughout this endeavor. I would also like to thank my committee members, Dr. Ralph Plummer, Dr. Gary Winn, Dr. Julie Patrick, and Dr. Dianne McMullin for their time and their helpful suggestions along the way. A special thanks goes to Dianne McMullin for her constant encouragement, friendship, and amusing emails during the last several years. She provided the laughter therapy that I needed. And finally, I want to thank all the people who volunteered their time to participate in the study - I could not have completed my dissertation without them. 


\section{TABLE OF CONTENTS}

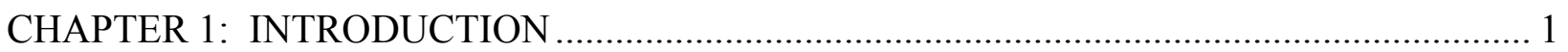

1.1 Information Processing ........................................................................................... 2

1.2 Distractions and Cognitive Processes .................................................................. 4

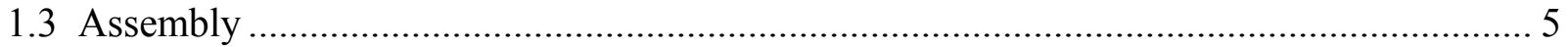

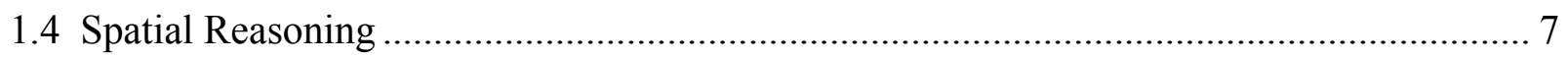

1.5 Field Independence and Distraction Resistance ................................................. 9

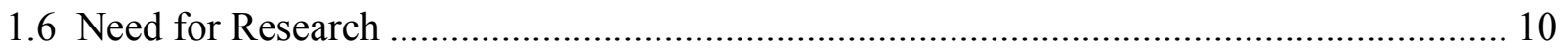

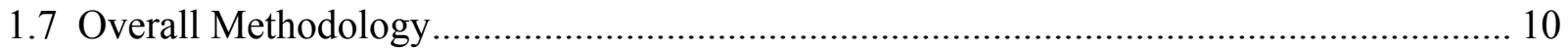

CHAPTER 2: METHODS AND MATERIALS ................................................................... 12

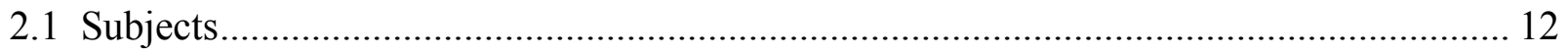

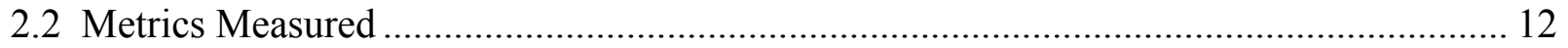

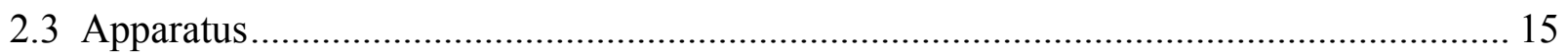

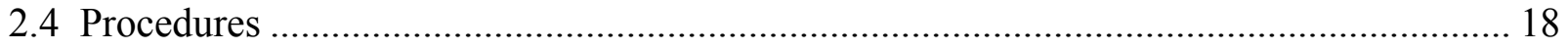

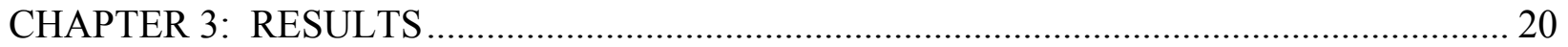

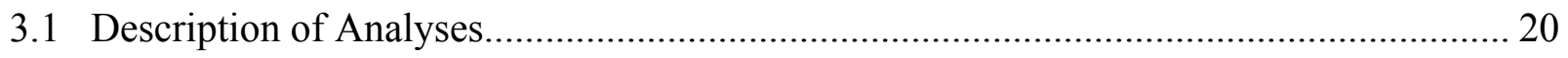

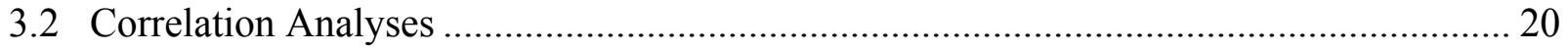

3.3 Number of Error Trials ........................................................................................ 24

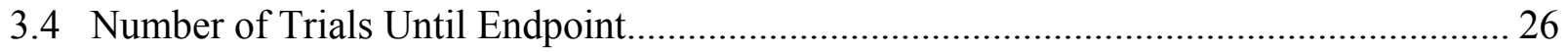

3.5 Number of Times the Video Was Watched............................................................ 28 
vi

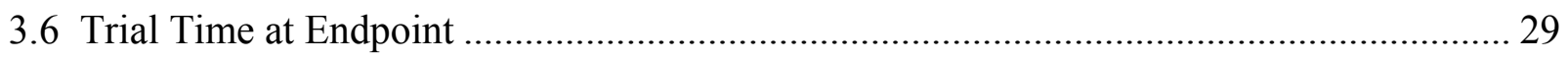

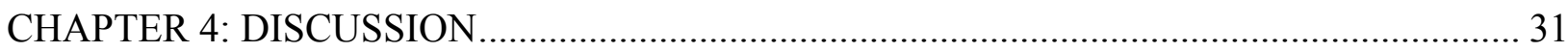

4.1 Spatial Reasoning Ability ................................................................................. 31

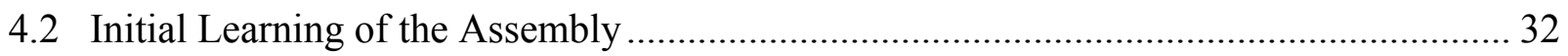

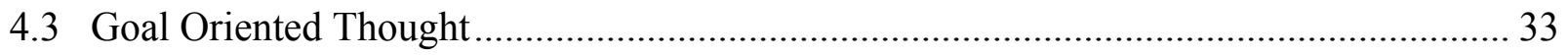

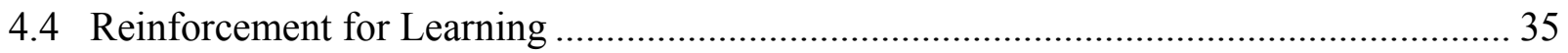

4.5 Effects of Distractors on Assembly Performance...................................................... 36

4.6 Aging Effects Related to the Timed Aspect of the Experiment .................................. 37

CHAPTER 5: CONCLUSIONS, RECOMMENDATIONS, AND SUGGESTIONS FOR

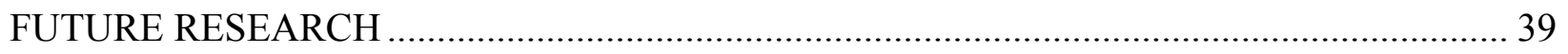

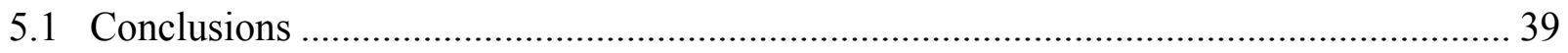

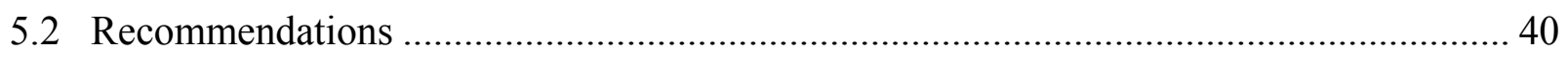

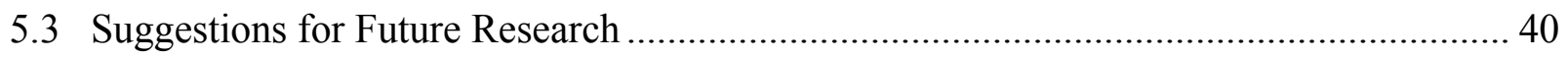

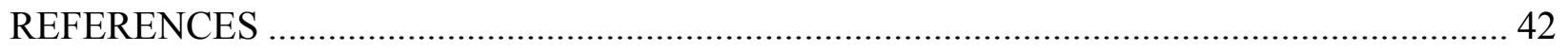

APPENDIX A — Transcription of Auditory Distractors ................................................. 48

APPENDIX B — Code for Visual Basic Program ................................................................. 50

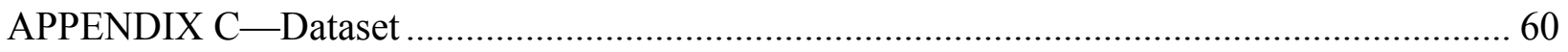

APPENDIX D_-Means for Error Trials Before a Correct Trial ......................................... 62

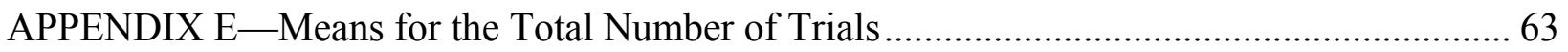


APPENDIX F-Means for the Number of Times the Instructional Video was Watched........... 64

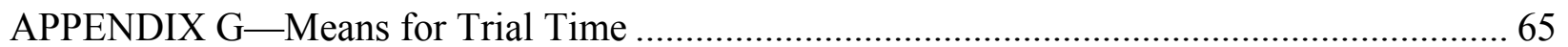

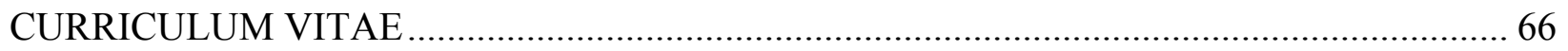




\section{LIST OF TABLES}

Table 1: Age, Field Independence Score (FIS), Spatial Reasoning Score (SR), and Years of Formal Education (YFE) for Each Age Group Studied (Gender not significant at $\operatorname{Pr}>\mathrm{F}=$

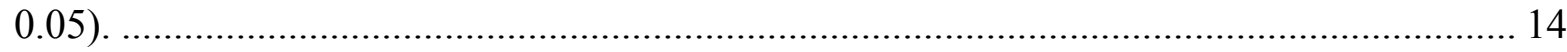

Table 2. MOST Calculation for the Assembly Task............................................................. 16

Table 3. Pearson Correlation Coefficients for the Dependent Variables, Age, and Covariates .. 23

Table 4. Analysis of Covariance for Number of Error Trials Before a Correct Trial................ 24

Table 5. ANCOVA for Number of Trials until Endpoint ...................................................... 27

Table 6. ANCOVA for the Number of Times the Video was Watched ................................. 28

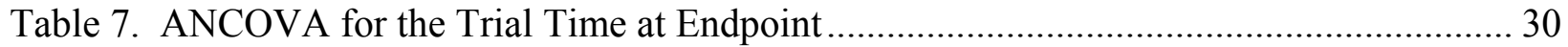




\section{LIST OF FIGURES}

Figure 1. Photograph of the Assembly that was used in this experiment .............................. 15

Figure 2. Experimental Work Station ................................................................................. 18

Figure 3. Pearson Correlation Coefficients presented in a Correlogram for Dependent Metrics,

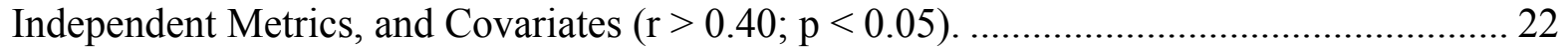

Figure 4. Adjusted Means of Dependent Variables by Age Group and Distractor Condtion ..... 25 


\section{CHAPTER 1: INTRODUCTION}

Many jobs require learning and performance of psychomotor tasks in the presence of distractions. Human performance in these situations depends not only on learned skills, but upon the ability to perform within a context that is attention demanding. Selective or focused attention, information processing, rehearsal in working memory and other cognitive processes have been argued to be potentially sensitive to both distraction and the aging process.

Distractions are those events that interrupt the information processing system and affect performance, usually cognitive skills that are mediated by either visual or auditory stimuli. Laboratory results have shown that irrelevant speech can disproportionately affect older adults (Rouleau and Belleville, 1996) and research on the deleterious effects of visual stimuli have been reported since the 1960's (Rabbitt, 1965).

Within this decade, Americans aged 55 and older will represent 30.0 percent of the population and 36.8 percent of the labor force (Fullerton, 1999). Many occupations that require continuous learning of manual or psychomotor performance tasks are likely to be populated by an ever-aging workforce (Braddock, 1999). If the interplay of aging and distraction is a determinant to work quality or quantity, then such information would be useful in developing workforce selection, work design, or distractor mediation strategies or protocols.

Older adults have performed poorer than young adults in tasks that require activity recall, and in motor activities that require effortful processing at high speeds (Lichty et. al., 1986, Park and Schwarz, 2000, Ratner et. al, 1988, and Wishart et. al, 2000). The contextual support hypothesis, which maintains a significant age by task interaction for recall and suggests that motor activities are more easily recalled than cognitive activities because they leave a 
multimodal memory trace (visual, tactile, and kinesthetic), has been challenged in recent work (Lichty et. al., 1986).

\subsection{Information Processing}

Perception of germane auditory and visual stimuli is requisite for information processing and learning. Auditory or visual distractors, however, compete for cognitive and working memory resources and can disrupt learning and recall that are required for learning or associative recall (Wickens, 1992). This problem may be more problematic in older adults whose visual and auditory perception are already challenged (Welford, 1985).

Short term memory refers to information that is maintained "in mind" after several stimuli have been presented. Short-term memory can be categorized into primary memory and working memory. Primary memory refers to information fragments that are still held in mind (span paradigms) whereas working memory involves manipulation, storage, and transformations of information over short time spans, e.g. mental calculations (Park and Schwarz, 2000). Research has indicated that age-related differences are slight in primary memory tasks but substantial in working memory tasks. Performance in working memory tasks decreases through adulthood and task difficulty may play a role in the degree of age-related decline (Park and Schwarz, 2000). Declines found in working memory performance with age are thought to result from a decline in attentional resources (Craik and Byrd, 1982), processing speed (Salthouse and Somberg, 1982), or the inability to inhibit irrelevant information (Hasher and Zacks, 1988). 
Age decrements in information processing may result from overall organic neuorological degradation that affects the entire system or differential slowing of components within the system (Birren and Schaie, 1990). The view that age contributes to a slowing of the entire information processing system, and not particular stages, was termed the "Generalized Slowing Hypothesis". Within this model, changes in the rate of information processing are related to the amount (capacity), and not the type, of information processing. Cross-sectional and longitudinal laboratory tests have shown that as adults age they become slower and less accurate in certain types of responses; particularly in simple and complex reaction time tests (Salthouse and Somberg, 1982 and Welford, 1985).

Human aging may have the potential to interact with the role of distractions in several ways. First, attentional control that may change with increasing age could affect one's performance on focused attention tasks (Rogers, W.A. and Fisk, A.D., 2001). Second, older adults could experience reductions in perceptual or motor bandwidth capacity thereby slowing information processing rates. Third, reduced inhibitory processes present in older adults could lead to the addition of irrelevant information entering the information processing system and competing for available resources (Hasher and Zacks, 1988; Zacks and Hasher, 1997). This is known as the interference model, and it states that older adults' attentional resources are more vulnerable to interfering effects of competing stimuli.

In sum, people can have overall slowing (main effect for age) or a distraction related effect (age*distraction interaction). Any possible decrements because of distractions may not be linear with increasing age, but may accelerate between different levels of distraction (Welford, 1962). 
With regards to motor control, Wishart, Lee, Murdoch, and Hodges (2000) found that both older and younger adults showed no differences in performance during in-phase tasks regardless of limb movement velocity. Age differences were found in anti-phase movement tasks at higher speeds.

Attentional training has been studied to find ways in which individuals can improve their performance in the face of distractions. Singer et. al. (1991) conducted an experiment to test the effects of attentional training on the performance of a motor task. Subjects were instructed to throw paddleballs at a target, and their accuracy was measured. Subjects were exposed to different levels of training (training or no training) and four different levels of distractors (no distractor, noise, light, noise and light). Subjects were assigned to one of the eight treatments. Results showed the attentional-focus group was more accurate and consistent than the no training group. In addition, distractor groups that received attention training displayed less absolute constant error and total variability across several of the trial blocks.

\subsection{Distractions and Cognitive Processes}

The two common types of exercises that test the role of distraction on cognitive performance are the Negative Priming Test and the Stroop Test. The Stroop Test measures the retention of automatized components in reading. In the Stoop test the subject is presented with colored word that is presented in a different colored ink. For instance, the word "purple" in yellow ink. The subject is asked to name the ink color, but subjects will tend to read the word (instead of yellow, they would say purple). The more the component is automatized, the greater 
is the degree of interference in this task. In the Negative Priming Test, the subject is presented with two pairs of letters. The target and the distractor are identified on the first pair that is shown. On the second pair, the distractor from the first task becomes the target on the second task (therefore the name, negative priming). Results have shown that there is an increased reaction time to identify the target when it has served as the distractor on the immediately previous trial. This suppression is termed inhibition, and it has been shown to be reduced in older adults (Zacks and Hasher, 1997).

Maylor and Lavie (1998) studied age differences in selective attention using a task that involved target identification in the presence of a distractor (letters) under varying levels of visual target set sizes. Older subjects were disproportionately affected by the distractor when set size, or perceptual load, was small. This research suggests that older adults may only differentially suffer from effects of distractors when perceptual loads are low enough to allow attentional resources to be devoted to the distractors.

\subsection{Assembly}

The learning rate for an operation is dependent not only on the improvement of psychomotor skills through repetition, but also on the transmission efficiency of the information being processed (Goldman and Hart, 1965). This approach is often used in industrial situations to forecast the length of learning time that workers must be given before achieving a performance standard. 
Research on aging and learning has shown that movement times increase with age and that increased task difficulty exacerbates the age differences (Ketcham, C.J. and Stelmach, G.E., 2001). Hancock (1967) found that learning times for manual operations became substantially longer for persons over the age of 40 unless the person had previous related experience.

Presentation mode and task complexity have been found to affect the learning rate for electronic assemblies (Goldman and Hart, 1965). Older adults have been shown to retain more knowledge and perform faster when instructions were given in video form than in written form (Mykityshyn, Fisk, and Rogers, 2002).

With trends in manufacturing towards small-batch, non routine work, research has begun to focus on the cognitive aspects of assembly work (Shalin, Prabhu, and Helander, 1996). Prabhu, Helander, and Shalin (1995) showed that product structure influenced the number of trials to learn an assembly, the time it took to learn an assembly, and the average completion time for the assembly. Their study showed that subjects performed faster with the vertical product structure than with the hierarchical product structure, even though both structures had an identical number of parts and both needed the same standard time according to a MOST analysis. They accounted for these differences by using information analysis (the information content for the hierarchical structure was greater than that of the vertical structure) and gestalt principles of perception. 
1.4 Spatial Reasoning

Spatial ability can be measured by one's performance on a test that measures one's ability to correctly mentally rotate figures in space (Shepard and Metzler, 1971). Decision time increases linearly with a linearly increasing difference in the number of degrees of rotation that separate the orientation of each object.

Gaylord and March (1975) studied age differences in the speed of spatial cognitive processes and determined that older subjects responded slower on a spatial task that required them to mentally rotate objects. In their study, the rate of mental rotation by the older subjects was $84 \%$ greater.

Vandenberg and Kuse (1978) modified the Shepard and Metzler test and produced a paper and pencil test of spatial visualization (termed the Mental Rotations Test). The test has been validated (test-retest correlation of .83) and there are indications of gender differences (with males having higher scores) and age related differences (with decreasing scores with decreasing age).

Jacewicz and Hartley (1979) studied mental rotation but they used letters instead of block forms. They found that with letters from the English alphabet, no differences existed between younger and older subjects with respect to basic speed or rate of manipulation. However, when they substituted non-familiar, lower-case Greek letters, the basic speed of older subjects was less than that of younger subjects. They concluded that their results were inconsistent with the hypothesis of generalized slowing of central nervous system activity. For this experiment, the mean age of the younger subjects was 21.2 years and the mean age of the older subjects was 56.5 years. All subjects (both young and old) were university students. 
Cerella, Poon and Fozard (1981) questioned Jacewicz's and Hartley's findings and repeated their experiment with a subject pool closer to that of Gaylord and Marsh. Their study recruited only female subjects. The mean age for the younger group was 21 years and the mean age for the older group was 72 years. Cerella et. al. found an age-difference of $96 \%$ on the mental rotations experiment with no differences in the error rates for the two age groups. They suggested that the reason for no age-related difference in Jacewicz's and Hartley's study might have been because they recruited younger, more active subjects.

Salthouse et. al. (1990) studied the effect of experience on spatial visualization. They studied the spatial ability skills of 50 men aged 24 to 67 who were all college educated and either practicing or recently retired architects. Salthouse et. al. (1990) demonstrated that age-related decrements in spatial visualization exist for groups of men who either practiced their spatial visualization skills daily (a group of architects) and those who didn't. The results suggested that some elements of cognitive processing may be independent of the effect of experience.

Research has also explored ways in which older adults can compensate for deficits in spatial memory. Clarkson-Smith and Halpern (1983) conducted a mental rotations test with verbal labels under each of the objects. The objects were four semi-ambiguous figures and there were either meaningful labels or non-meaningful labels underneath of the objects. They studied women in three age groups: Young $(M=21.3$ years, range $=18-28)$, Young-Old $(M=54.7$, range $=50-60$ years $)$ and Old-Old $(\mathrm{M}=74.2$ years, range $=70-80)$. They found that errors increased as a function of age (oldest group was significantly different from other two groups) but that meaningful labels were beneficial in proportionally decreasing errors for the oldest group. 
1.5 Field Independence and Distraction Resistance

Field independence was originally proposed by Herman A. Witkin as a concept that described a person's perception of their geocentric orientation. Eventually, the concept was expanded to include a person's ability to separate an item from an organized field. Field Independence can be measured by tests that either judge the person's ability to perceive the upright (Rod and Frame Test (RFT), Body Adjustment Test (BAT), Rotating Room Test (RRT)), or by tests that evaluate one's ability to identify an item that has been embedded within a field (Embedded Figures Test, EFT) (Witkin and Goodenough, 1981). Metrics of field dependence are scalars with no arbitrary threshold for classification.

The notion that field independence allows a person to selectively attend to certain information within the field while ignoring other irrelevant information has led to the exploration of whether field independence is related to the ability to resist distractions. Research conducted during the last 35 years has proved to be inconclusive in this area.

Bloomberg (1965) found that field independent subjects were less affected by distractors in a reversible perspective task. Blowers (1974 and 1976) concluded that field independence didn't affect reaction time performance. Karp (1963) found, using factor analysis, that embeddedness tests loaded and contributed to different factor structures than did distraction metrics; although the factors tended to be moderately correlated. Makkar (1999) found fieldindependent subjects were less susceptible to distraction in short-term memory test.

Field independence appears to change with age. Field independence improves between 8 to 15 years of age, then stabilizes, and in later life field independence decreases (Witkin et. al., 1971; Schwartz and Karp, 1967; Panek, 1985). Males between 60 and 75 years of age, who were 
still working, have been found to be significantly more field-independent than retired cohorts (Karp, 1967).

Research on the relationship between Field Dependence and gender has been mixed. While Witkin et. al., (1971) demonstrated differences between the sexes in field independence, later studies have not supported that previous work and have shown no significant sex differences in younger or older adults (Panek, 1985).

\subsection{Need for Research}

Demographics combined with a change in cultural norms that encourages older citizens to remain active will support greater numbers of older workers in the workplace (Fullerton, 1997). Many of the jobs available will demand worker performance in the presence of distractors that may enter the information processing system through different channels. Although information processing and attentional capacities have been shown to decrease in older adults, many studies have not attempted to determine if those changes are significant enough to cause work related decrements. In addition, studies on distraction have largely concentrated on changes in visual selective attention and have not determined possible effects on an assembly task.

\subsection{Overall Methodology}

This research project was designed to answer a very specific question: Do distractions differentially affect different aged people in the early stages of learning a visuospatial task? An 
assembly task was chosen because it can be seen to represent the skills, such as selective attention, manual dexterity, and visualization, required for tasks involved in either service (fastfood) or manufacturing (Fleishman and Reilly, 1992). The early stage of learning was chosen because it was hypothesized that if distractions affected performance, it would be most significant in the early phases. The multiple resource theory was chosen as a theoretical basis for the choice of distractors. Covariates that could influence learning and ameliorate age differences, such as Field Independence, Years of Formal Education, and Spatial Reasoning, were considered. 
CHAPTER 2: METHODS AND MATERIALS

\subsection{Subjects}

Sixty-six male and female subjects between the ages of 18 and 65 years participated in this study on an informed consent and unpaid basis (42 females and 24 males). One subject's data was considered to be an outlier ( $\mathrm{M}$ for trial time was $>2.5 \mathrm{x} \mathrm{M}$ for other scores within the subject's group) and was dropped. Subject age range was selected to represent adult working population.

\subsection{Metrics Measured}

For each subject four dependent metrics and three covariates were collected. The dependent variables were: 1) number of error trials before the subject was able to complete an error free trial, 2) number of times the instructional video was watched, 3) number of trials it took the subject to reach the stopping criterion (three consecutive correct trials), and 4) trial time for the final trial. The covariates that were collected were: 1) field independence score (FIS, scores were from 0-18 with 18 representing someone who is very field independent; field independence has been correlated with resistance to distractors), 2) spatial reasoning (SR, scores were from 0-40 with greater spatial reasoning associated with a higher score; greater spatial reasoning would enhance one's performance on the assembly task), and 3) years of formal education (YFE, score ranged from 12 to 20, more years of education being associated with a greater ability to learn). All subjects completed the assembly task first. Subjects were then brought back to take the tests for the covariate measures. Subjects were administered a Group 
Embedded Figures Test to obtain a measure of field independence following the methods described by Witkin et. al. (1971). The Vandenberg Mental Rotation Test was administered to measure spatial reasoning ability following the methods outline by Vandenberg and Kuse (1978). SPSS Version 11.5.1 was used for the statistical analysis. Table 1 provides summary data for the subjects on the covariates. 
Table 1: Age, Field Independence Score (FIS), Spatial Reasoning Score (SR), and Years of Formal Education (YFE) for Each Age Group Studied (Gender not significant at $\operatorname{Pr}>\mathrm{F}=0.05$ ).

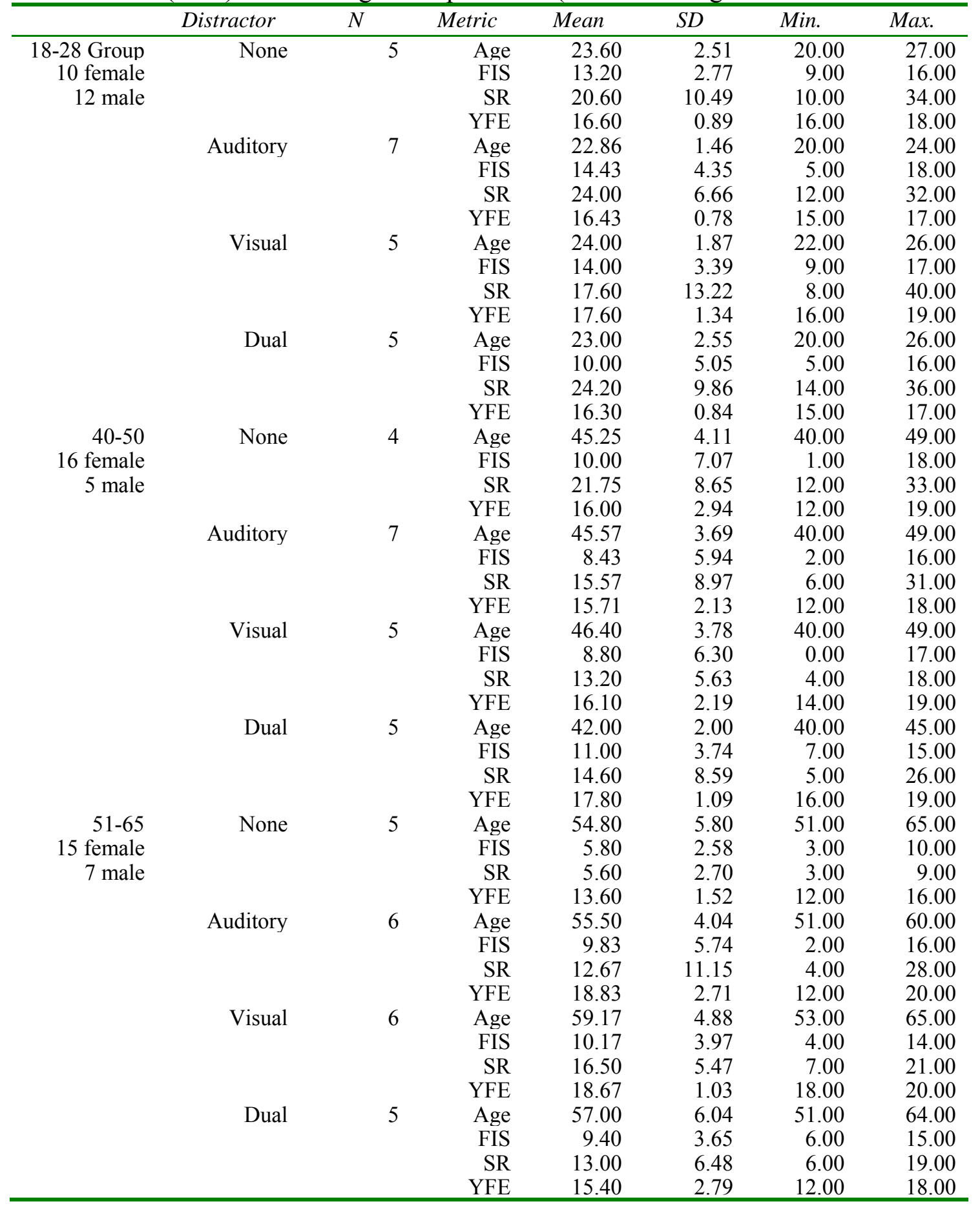


A microcomputer with a $43.18 \mathrm{~cm}$ (diagonal), $640 \times 480$ dpi visual display was used to present an instructional video delineating the required spatial and color configuration of 9 large red, blue, green and yellow 4 to 12 connector Lego Duplo ${ }^{\mathrm{TM}}$ blocks. The blocks were chosen for their size to reduce potential age-related problems with grip and hand dexterity. The Duplo blocks that were used were $1.9 \mathrm{~cm}$ high, $3.18 \mathrm{~cm}$ wide, and either $3.18,6.36$, or $9.53 \mathrm{~cm}$ long. Color and size of blocks and the spatial organization of the assembly tasks were noncontextual or hierarchical to avoid environmental support. The MOST standard time for this operation was calculated to be 19.44 seconds. A photograph of the assembly is shown in Figure 1.

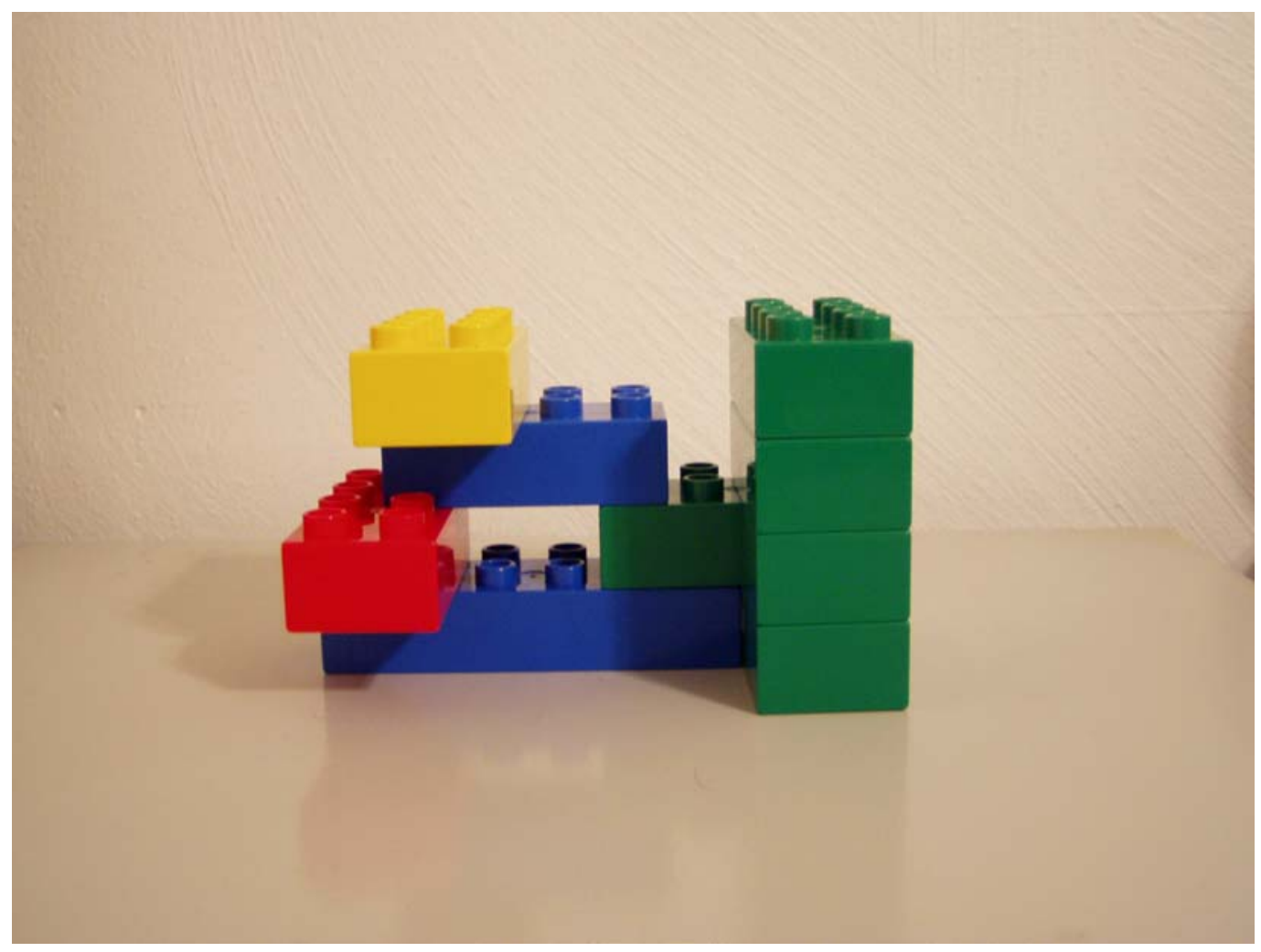

Figure 1. Photograph of the Assembly that was used in this experiment 
The MOST calculation for the task is found in Table 2.

Table 2. MOST Calculation for the Assembly Task

\begin{tabular}{llr}
\hline \multicolumn{4}{l}{ MOST Calculation } & \\
\hline \multicolumn{1}{l}{ Assembly Task } & & \\
No. Method & Sequence Model & 60 \\
1 Get and put blue block & $\mathrm{A}_{1}, \mathrm{~B}_{0}, \mathrm{G}_{1}, \mathrm{~A}_{1}, \mathrm{~B}_{0}, \mathrm{P}_{3}, \mathrm{~A}_{0}$ & 60 \\
2 Get and put green block & $\mathrm{A}_{1}, \mathrm{~B}_{0}, \mathrm{G}_{1}, \mathrm{~A}_{1}, \mathrm{~B}_{0}, \mathrm{P}_{3}, \mathrm{~A}_{0}$ & 60 \\
3 Get and put green block & $\mathrm{A}_{1}, \mathrm{~B}_{0}, \mathrm{G}_{1}, \mathrm{~A}_{1}, \mathrm{~B}_{0}, \mathrm{P}_{3}, \mathrm{~A}_{0}$ & 60 \\
4 Get and put red block & $\mathrm{A}_{1}, \mathrm{~B}_{0}, \mathrm{G}_{1}, \mathrm{~A}_{1}, \mathrm{~B}_{0}, \mathrm{P}_{3}, \mathrm{~A}_{0}$ & 60 \\
5 Get and put green block & $\mathrm{A}_{1}, \mathrm{~B}_{0}, \mathrm{G}_{1}, \mathrm{~A}_{1}, \mathrm{~B}_{0}, \mathrm{P}_{3}, \mathrm{~A}_{0}$ & 60 \\
6 Get and put blue block & $\mathrm{A}_{1}, \mathrm{~B}_{0}, \mathrm{G}_{1}, \mathrm{~A}_{1}, \mathrm{~B}_{0}, \mathrm{P}_{3}, \mathrm{~A}_{0}$ & 60 \\
7 Get and put green block & $\mathrm{A}_{1}, \mathrm{~B}_{0}, \mathrm{G}_{1}, \mathrm{~A}_{1}, \mathrm{~B}_{0}, \mathrm{P}_{3}, \mathrm{~A}_{0}$ & 60 \\
8 Get and put yellow block & $\mathrm{A}_{1}, \mathrm{~B}_{0}, \mathrm{G}_{1}, \mathrm{~A}_{1}, \mathrm{~B}_{0}, \mathrm{P}_{3}, \mathrm{~A}_{0}$ & 60 \\
9 Get and put green block & $\mathrm{A}_{1}, \mathrm{~B}_{0}, \mathrm{G}_{1}, \mathrm{~A}_{1}, \mathrm{~B}_{0}, \mathrm{P}_{3}, \mathrm{~A}_{0}$ & \\
& & \\
Time $=19.44$ sec & & \\
\hline
\end{tabular}

Blocks were organized and stored in bins according to color at an equal distance of $26 \mathrm{~cm}$ from the center of the assembly platform. The assembly platform was $37.47 \mathrm{~cm}$ long, $25.4 \mathrm{~cm}$ wide, and $15.24 \mathrm{~cm}$ high (off the table). Two storage bins were located on the left of the assembly platform and two on the right of the assembly platform. The bin height was equal to the assembly platform. Individual bin size was $5.4 \mathrm{~cm}$ high, $12.38 \mathrm{~cm}$ wide and $15.88 \mathrm{~cm}$ long.

The four distractor conditions, constructed to be representative of the types of distractions that are encountered in industry, are described below:

1. No Distractors. A digital picture that showed the same person as was seen in the video portion was shown full screen. 
2. Verbal Distraction. A female voice presented continuous and unrelated commentary. Verbal recordings were approximately $27 \mathrm{~s}$ in duration and consisted of, on average, 98 words in ten-word sentences that were presented at 68-70 dBA SPL. Four different verbal recordings were used were presented across trials on a random-order basis.

3. Visual Distraction. A video of an unrelated block assembly task, displayed as a mirror image, was presented in front of the subject within their center of the field of view, to resemble an image of a worker sitting across from the assembly station performing a different assembly task. The video played the assembly task continuously until the experimental trial was completed.

4. Combined Verbal and Visual Distraction. Verbal and visual distractors were presented simultaneously.

The experimental task setup and view of the distractor monitor, along with measurements, are provided in Figure 2. A visual basic program was written to run the experiment, to present the instructional videos and distractions to the subjects, to time the subject, and to record the data in a systematic fashion. 


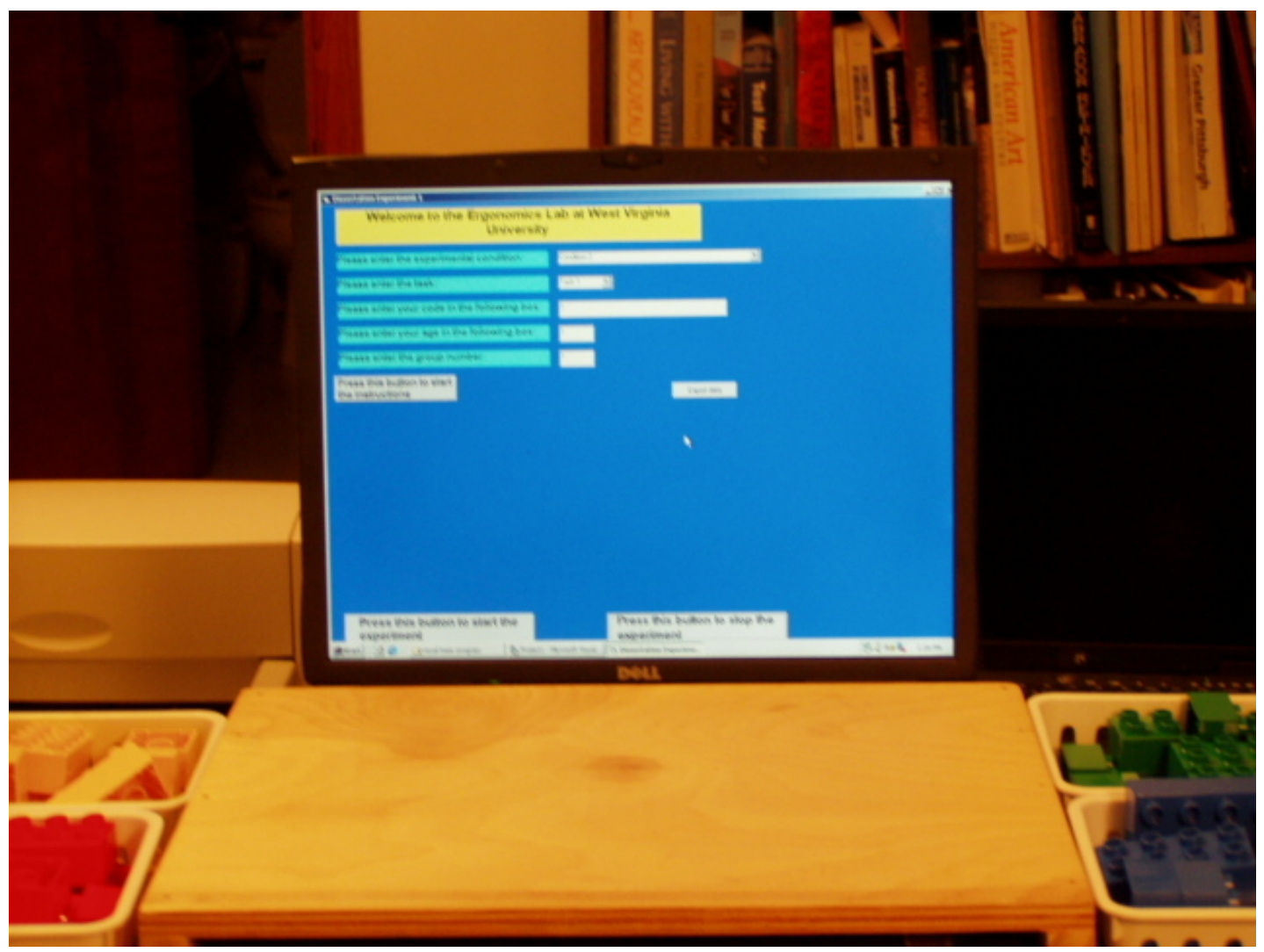

Figure 2. Experimental Work Station

Note: Distance to screen from subject is $50 \mathrm{~cm}$ and distance from center of person to blocks is $40 \mathrm{~cm}$.

\subsection{Procedures}

Following a standardized description of the experimental objectives, paradigm, procedures, and completion of informed consent form, a subject was randomly assigned to one of the distractor conditions. The subject sat at the assembly station and was given an opportunity to practice reaching for, moving and assembling the blocks in various patterns. 
Upon completion of self-paced practice, the subject was shown a video of the block assembly task. The instructional video showed a person building the assembly. The instructional video contained no audio and provided a subject's eye view of the step-by-step assembly task. The timed experimental trials then followed immediately.

The subject was instructed to complete the task as quickly and as accurately as possible. If the subject made a mistake, the subject was stopped and the trial was restarted after rewatching the assembly instruction video. Mistakes consisted of either an incorrect block location or color of block. Subjects were not required to re-watch the instruction video if they felt that they fully understood the assembly process. Once a subject completed three error-free trials, the experiment was stopped by the computer. The time per subject for the assembly component of the experiment ranged from 20-25 minutes. After all subjects had completed the assembly portion of the experiments, subjects were brought in a second time so that the Group Embedded Figures Test and the Spatial Reasoning test could be administered. The results of these two tests served as covariates. 
CHAPTER 3: RESULTS

\subsection{Description of Analyses}

Four dependent variables were analyzed: number of error trials before a correct trial, number of total trials needed to complete the experiment, number of times the video was watched, and trial time for the third correct consecutive trial. In addition, error trials made after a correct trial were analyzed as a part of the analysis for total number of trials. The class variables used in the analyses of covariance were age group (18-28, 40-50, and 51-65 years) and distractor condition (none, auditory, visual, auditory + visual). Covariates that were included in the analyses were spatial reasoning (SR), field independence (FIS), and years of formal education (YFE). Field independence and spatial reasoning were collected after subjects had already been assigned to a distractor condition. The statistical power for determining either a $10 \%$ effect for trial time or at least a difference of one trial was $90 \%$ or greater. Analysis of covariance was done according to the methods set forth in Neter et. al. (1990).

\subsection{Correlation Analyses}

Correlation analyses were done to determine possible relationships between variables (both independent and dependent). Age was significantly, but weakly (nothing greater than $r=.425$ ), positively correlated with all dependent metrics. Field independence was negatively and significantly correlated with all dependent measures $(\mathrm{r}<-.368)$. This indicated that the more

field independent the person was, the better the measure on the dependent metric. Because the correlations were relatively weak, they did not show up as significant on the ANCOVA. In 
addition, FIS was significantly and negatively correlated with age $(r=-.381)$ and significantly and positively correlated with SR $(r=.534)$. Spatial reasoning was significantly and negatively correlated with all the dependent measures and age. The strongest relationship was $r=-.516$ between spatial reasoning and the number of times the video was watched. Years of formal education (YFE) was not significantly correlated with any of the dependent metrics. These results are shown in Figure 3 and Table 3. 


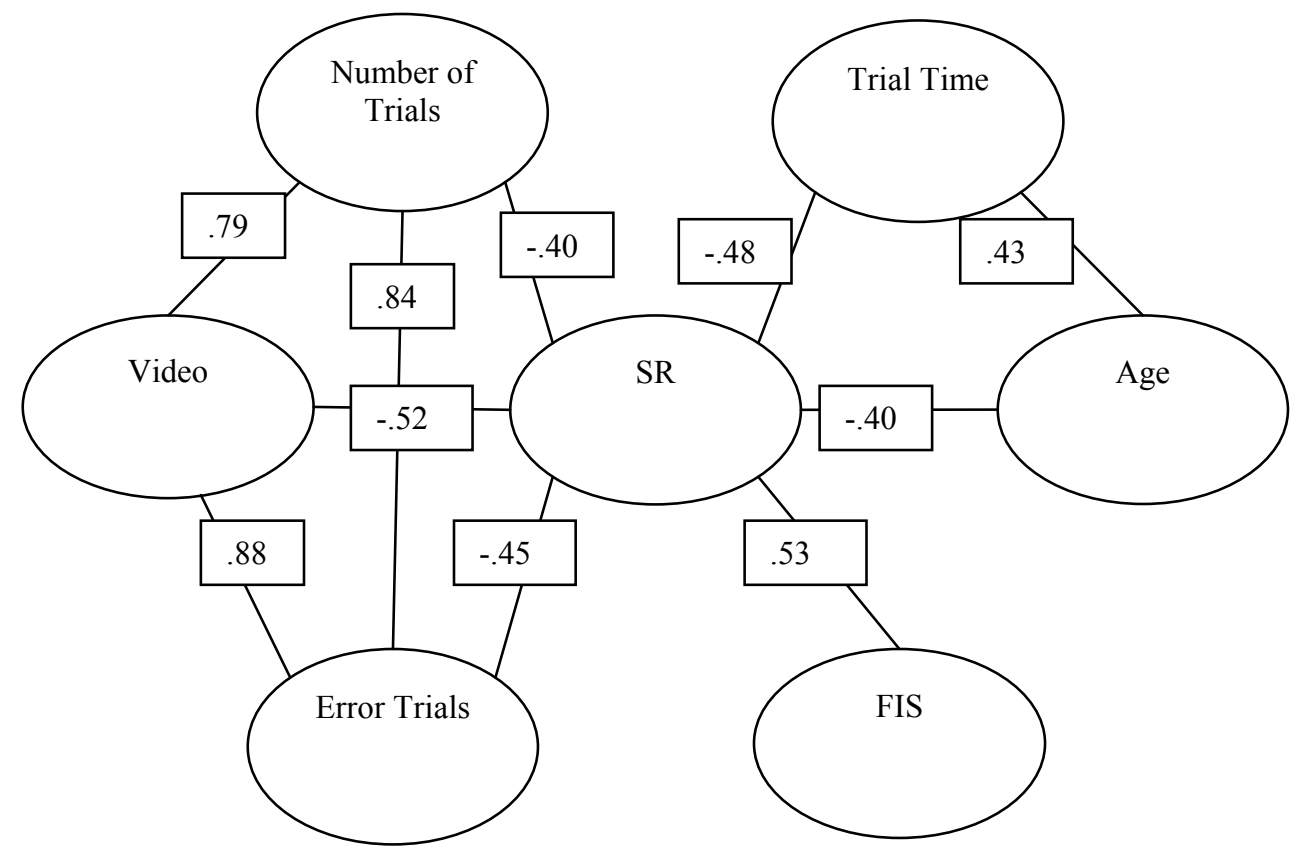

Figure 3. Pearson Correlation Coefficients presented in a Correlogram for Dependent Metrics, Independent Metrics, and Covariates $(\mathrm{r}>0.40 ; \mathrm{p} \leq 0.05)$.

NOTE: Age is age of subject, and Video is number of times the video was watched, FIS is Field Independence Score, SR is Spatial Reasoning Ability, and YFE is Years of Formal Education. 
Table 3. Pearson Correlation Coefficients for the Dependent Variables, Age, and Covariates

\begin{tabular}{|c|c|c|c|c|c|c|c|c|}
\hline Measure & 1 & 2 & 3 & 4 & 5 & 6 & 7 & 8 \\
\hline $\begin{array}{l}\text { Number of times the } \\
\text { video was watched }\end{array}$ & 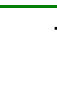 & $.880(* \star)$ & $.793\left({ }^{\star \star}\right)$ & $.346\left({ }^{* *}\right)$ & $.345(* \star)$ & $-.338\left(^{(\star *}\right)$ & $-.516\left({ }^{\star \star}\right)$ & .210 \\
\hline $\begin{array}{l}\text { Error Trials Before a } \\
\text { Correct Trial }\end{array}$ & & - & $.837(\star \star)$ & .210 & $.282\left(^{*}\right)$ & $-.245\left(^{*}\right)$ & $-.450(* \star)$ & .139 \\
\hline Total Trials & & & - & .110 & $\left..318^{(\star *}\right)$ & $-.315\left(^{*}\right)$ & $-.403\left({ }^{* \star}\right)$ & .073 \\
\hline Trial Time & & & & - & $.425(* \star)$ & $\left.-.368^{(\star \star}\right)$ & $-.475\left(^{\star \star}\right)$ & -.030 \\
\hline Age & & & & & - & $-.381(\star \star)$ & $-.402(* \star)$ & -.138 \\
\hline $\begin{array}{l}\text { Field Independence } \\
\text { Score } \\
\text { Spatial Reasoning }\end{array}$ & & & & & & - & $.534(\star \star)$ & $\begin{array}{r}.206 \\
-.036\end{array}$ \\
\hline $\begin{array}{l}\text { Years of Formal } \\
\text { Education }\end{array}$ & & & & & & & & - \\
\hline
\end{tabular}

** Correlation is significant at the 0.01 level; * Correlation is significant at the 0.05 level; $N=65$. 


\subsection{Number of Error Trials}

Number of error trials needed before the subject was able to complete a correct trial was collected as a measure of one's memory for a spatial task in the face of auditory or visual distractors. No significant main effects or interactions were found for an Age x Distractor ANCOVA that was performed on the number of error trials. Spatial Reasoning was, however, found to be a significant covariate. A complete ANCOVA table can be found in Table 4, a plot showing the adjusted means can be found in Figure 4, and a table listing the adjusted means can be found in Appendix D.

Table 4. Analysis of Covariance for Number of Error Trials Before a Correct Trial

\begin{tabular}{lrrrrr}
\hline Source & \multicolumn{1}{c}{ SS } & df & \multicolumn{1}{l}{ MS } & \multicolumn{1}{l}{$\mathrm{F}$} & $\mathrm{p} \leq$ \\
\hline Corrected Model & $81.975(\mathrm{a})$ & 14 & 5.855 & 2.045 & .033 \\
Intercept & .258 & 1 & .258 & .090 & .765 \\
Field Independence & .540 & 1 & .540 & .189 & .666 \\
Spatial Reasoning & 12.837 & 1 & 12.837 & 4.483 & .039 \\
Years of Formal & 8.983 & 1 & 8.983 & 3.137 & .083 \\
Education & 6.373 & 2 & 3.187 & 1.113 & .337 \\
Age Group (A) & .353 & 1 & .353 & .123 & .727 \\
Audio Distractor & .145 & 1 & .145 & .051 & .823 \\
(DA) & 15.141 & 2 & 7.571 & 2.644 & .081 \\
Visual Distractor & 1.016 & 2 & .508 & .177 & .838 \\
(DV) & 2.581 & 1 & 2.581 & .902 & .347 \\
A X DA & 7.202 & 2 & 3.601 & 1.258 & .293 \\
A X DV & & & & & \\
DA X DV & 143.163 & 50 & 2.863 & & \\
A X DA X DV & 878.000 & 65 & & & \\
Error & 225.138 & 64 & & & \\
Total & & & & & \\
Corrected Total & & & & & \\
\hline R Squared & & & & & \\
\hline
\end{tabular}

a R Squared $=.364$ (Adjusted R Squared $=.186$ ) 


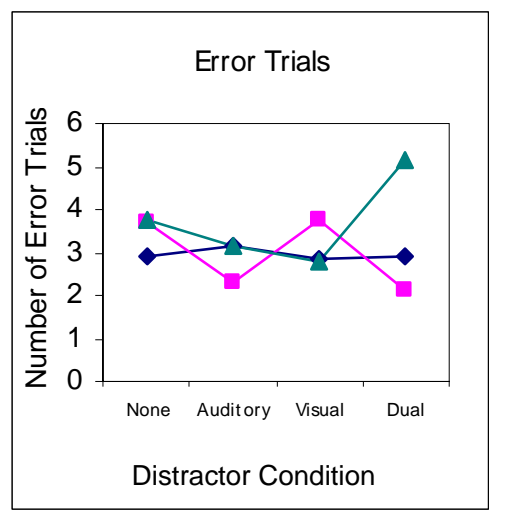

a)

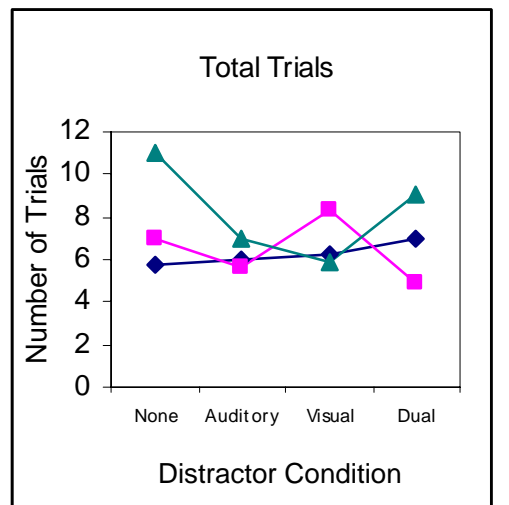

b)

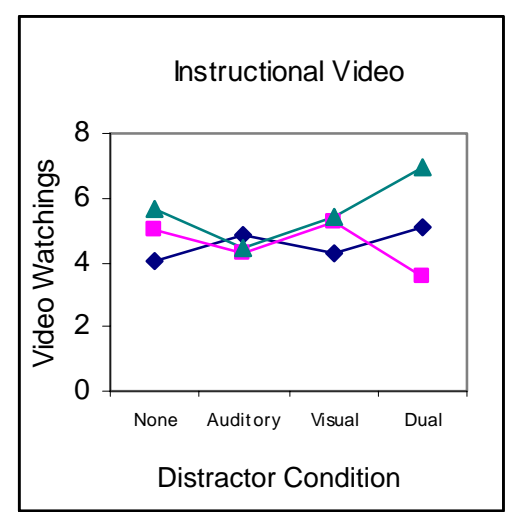

c)

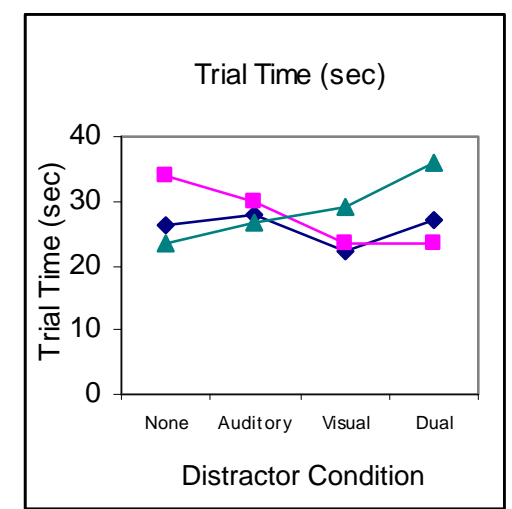

d)

Figure 4. Adjusted Means of Dependent Variables by Age Group and Distractor Condtion: a) Number of Error Trials Before a Correct Trial, b) Number of Total Trials, c) Number of Times the Instructional Video was Watched, and d) Trial Time. Lines Represent Age Groups: $\bullet$ Age 18-28, $\square=$ Age 40-50, and $\Delta=$ Age 51-65. 


\subsection{Number of Trials Until Endpoint}

Number of trials was investigated to determine if age and distractor condition had an effect on the amount of trials needed to complete three consecutive correct trials (experimental endpoint). Any differences between these analyses and error trials before a correct trial reflected error trials being made after a subject had completed a correct trial. An Age x Distractor ANCOVA performed on the number of total trials found a significant age effect $(\mathrm{F}(2,50)=$ 3.910; $\mathrm{MSE}=4.832 ; \mathrm{p}<0.05)$ as well as an age $\mathrm{x} \mathrm{DA} \times \mathrm{DV}$ effect $(\mathrm{F}(2,50)=4.818 ; \mathrm{MSE}=$ 4.832; $\mathrm{p}<0.05)$. Post hoc tests showed that subjects who were 51 years or greater took significantly more trials than the younger groups (31\% over baseline), and they showed that subjects 51 or older with both distractors took more trials than the middle aged subjects (56\% over baseline). Years of Formal Education was found to be the only significant covariate for number of total trials. The complete ANCOVA for total number of trials can be found in Table 5, a plot showing the adjusted means can be found in Figure 4, and a table with the adjusted means can be found in Appendix E. 
Table 5. ANCOVA for Number of Trials until Endpoint

\begin{tabular}{|c|c|c|c|c|c|}
\hline Source & SS & df & MS & $\mathrm{F}$ & $p \leq$ \\
\hline Corrected Model & 193.868(a) & 14 & 13.848 & 2.866 & .003 \\
\hline Intercept & .076 & 1 & .076 & .016 & .901 \\
\hline Field Independence & 5.732 & 1 & 5.732 & 1.186 & .281 \\
\hline Spatial Reasoning & 2.154 & 1 & 2.154 & .446 & .507 \\
\hline $\begin{array}{l}\text { Years of Formal } \\
\text { Education }\end{array}$ & 36.803 & 1 & 36.803 & 7.617 & .008 \\
\hline Age Group (A) & 37.787 & 2 & 18.893 & 3.910 & .026 \\
\hline $\begin{array}{l}\text { Audio Distractor } \\
\text { (DA) }\end{array}$ & 9.670 & 1 & 9.670 & 2.001 & .163 \\
\hline $\begin{array}{l}\text { Visual Distractor } \\
\text { (DV) }\end{array}$ & .502 & 1 & .502 & .104 & .749 \\
\hline$A \times D A$ & 20.339 & 2 & 10.169 & 2.105 & .133 \\
\hline$A \times D V$ & 13.041 & 2 & 6.520 & 1.350 & .269 \\
\hline $\mathrm{DA} \times \mathrm{DV}$ & 13.571 & 1 & 13.571 & 2.809 & .100 \\
\hline$A \times D A \times D V$ & 46.559 & 2 & 23.279 & 4.818 & .012 \\
\hline Error & 241.578 & 50 & 4.832 & & \\
\hline Total & 3537.000 & 65 & & & \\
\hline Corrected Total & 435.446 & 64 & & & \\
\hline
\end{tabular}

The fact that the ANCOVAs for the number of error trials and number of total trials were not similar indicates that some subjects made error trials after making a correct trial and thus took longer to complete the experiment. Sixteen of the sixty-five subjects (approximately 25\%) made an error trial after making a correct trial. Of those 16 subjects, 3 were in the youngest group, 4 were in the middle aged group, and 9 were in the oldest group. Sixty-nine percent of the oldest group made an error trial after a completing the assembly correctly at least one time. Making a mistake was not related to whether a person experienced distractors. 
3.5 Number of Times the Video Was Watched

An Age x Distractor ANCOVA was performed on the number of times the instructional video was watched. No significant main effects or interactions were found for the number of times the instructional video was watched. The ANCOVA for the number of times the instructional video was watched can be found in Table 6 , a plot showing the adjusted means can be found in Figure 4, and a table listing the adjusted means can be found in Appendix F. Spatial Reasoning and Years of Formal Education were both found to be significant covariates.

Correlation analysis showed that spatial reasoning ability was inversely correlated with the number of times the video was watched and years of formal education was positively correlated with the number of times the video was watched.

Table 6. ANCOVA for the Number of Times the Video was Watched

\begin{tabular}{lrrrrr}
\hline Source & \multicolumn{1}{c}{ SS } & df & \multicolumn{1}{l}{ MS } & \multicolumn{1}{l}{$\mathrm{F}$} & $\mathrm{p} \leq$ \\
\hline Corrected Model & $136.271(\mathrm{a})$ & 14 & 9.734 & 2.990 & .002 \\
Intercept & 1.591 & 1 & 1.591 & .489 & .488 \\
Field Independence & 2.447 & 1 & 2.447 & .752 & .390 \\
Spatial Reasoning & 21.630 & 1 & 21.630 & 6.645 & .013 \\
Years of Formal & 15.792 & 1 & 15.792 & 4.852 & .032 \\
Education & 12.535 & 2 & 6.267 & 1.926 & .156 \\
Age Group (A) & .120 & 1 & .120 & .037 & .849 \\
Audio Distractor & 1.950 & 1 & 1.950 & .599 & .443 \\
(DA) & 10.442 & 2 & 5.221 & 1.604 & .211 \\
Visual Distractor & 4.288 & 2 & 2.144 & .659 & .522 \\
(DV) & 1.261 & 1 & 1.261 & .387 & .537 \\
A X DA & 7.115 & 2 & 3.557 & 1.093 & .343 \\
A X DV & & & & & \\
DA X DV & 162.744 & 50 & 3.255 & & \\
A X DA X DV & 1845.000 & 65 & & & \\
Error & 299.015 & 64 & & & \\
Total & & & & & \\
Corrected Total & & & &
\end{tabular}

a R Squared $=.456$ (Adjusted R Squared $=.303$ ) 
However, if the data were split between those who made an error trial after a correct trial and those who did not, the results are not similar. For the group who did not make an error trial after a correct trial, older adults watched the video more than the two younger groups $(\mathrm{F}(2,35)=2.953, \mathrm{p}=0.065)$. Older adults watched the video $23 \%$ more than did the youngest group.

\subsection{Trial Time at Endpoint}

An Age x Distractor ANCOVA performed on trial time at endpoint found an age x DV effect $(\mathrm{F}(2,50)=9.429 ; \mathrm{MSE}=31.226 ; \mathrm{p}<0.01) . \quad$ However, post hoc tests showed that increases in trial time with visual distractors only occurred if subjects were 51 years or greater in age. Trial time for the oldest group with a visual distraction was $25 \%$ higher than baseline. Spatial reasoning was found to be the only significant covariate. A complete ANCOVA can be found in Table 7, a plot showing the adjusted means can be found in Figure 4, and a table listing the adjusted means can be found in Appendix G. 
Table 7. ANCOVA for the Trial Time at Endpoint

\begin{tabular}{|c|c|c|c|c|c|}
\hline Source & SS & df & MS & $\mathrm{F}$ & $p \leq$ \\
\hline Corrected Model & 1763.310(a) & 14 & 125.951 & 4.034 & .000 \\
\hline Intercept & 622.167 & 1 & 622.167 & 19.925 & .000 \\
\hline Field Independence & 9.126 & 1 & 9.126 & .292 & .591 \\
\hline Spatial Reasoning & 398.338 & 1 & 398.338 & 12.757 & .001 \\
\hline $\begin{array}{l}\text { Years of Formal } \\
\text { Education }\end{array}$ & .081 & 1 & .081 & .003 & .960 \\
\hline Age Group (A) & 73.283 & 2 & 36.641 & 1.173 & .318 \\
\hline $\begin{array}{l}\text { Audio Distractor } \\
\text { (DA) }\end{array}$ & 70.723 & 1 & 70.723 & 2.265 & .139 \\
\hline $\begin{array}{l}\text { Visual Distractor } \\
\text { (DV) }\end{array}$ & 17.325 & 1 & 17.325 & .555 & .460 \\
\hline$A \times D A$ & 133.229 & 2 & 66.614 & 2.133 & .129 \\
\hline$A \times D V$ & 588.868 & 2 & 294.434 & 9.429 & .000 \\
\hline $\mathrm{DA} \times \mathrm{DV}$ & 53.006 & 1 & 53.006 & 1.697 & .199 \\
\hline$A \times D A \times D V$ & 1.077 & 2 & .539 & .017 & .983 \\
\hline Error & 1561.287 & 50 & 31.226 & & \\
\hline Total & 52316.535 & 65 & & & \\
\hline Corrected Total & 3324.598 & 64 & & & \\
\hline
\end{tabular}

Because some subjects appeared to reach asymptote while others did not, additional analyses were completed on that factor. Spatial reasoning was not equally divided between those who stabilized their times and those who did not. Subjects who reached asymptote had significantly faster trial times (22.66 sec compared with $30.65 \mathrm{sec}$; $\mathrm{t}(63)=-5.643, \mathrm{p}=<0.0001)$ and they had significantly better spatial reasoning skills $(19.65$ compared with $14.67 ; \mathrm{t}(63)=2.165, \mathrm{p}=$ 0.0342). 


\section{CHAPTER 4: DISCUSSION}

The learning of a manual assembly task was expected to be more difficult for older subjects and for subjects who completed the assembly while confronted by distraction due to challenges to memory and attentional processes. Older subjects were hypothesized to have more difficulties learning the task because of memory decrements for spatial processes. Using the multiple resource theory as a basis for the choice of distractors, it was hypothesized that the visual distractor would have more of a detrimental effect on performance than would the auditory distractor. The choice of intensity of the distractors was based upon what a person would experience in a normal service-industry setting. In addition, it was postulated that there would be an age $\mathrm{x}$ distractor effect because of reduction in the ability for older adults to focus their attention in the face of distractors. Three phases of learning were studied: the ability to learn the assembly (not a timed measured; two dependent variables related to it: number of error trials before a correct trial and number of times the video was watched), the ability to learn and maintain goal oriented thought (as measured by the total number of trials; if a person made an error trial after a correct one this metric would not match with the error trials metric) and the final trial time (speeded metric).

\subsection{Spatial Reasoning Ability}

The major finding of this study was that for this experimental paradigm, spatial reasoning ability was more important than age or distractor for the learning and performance of a manual assembly task. People who had better spatial reasoning took fewer trials to initially learn the 
assembly, took fewer trials to complete the experiment, watched the instructional video fewer times, and had faster trial times than those persons with poorer spatial ability. Spatial reasoning provided a protection against possible psychomotor decrements due to normative aging changes.

The measurement of spatial reasoning ability involves the manipulation of three dimensional objects during a timed experimental testing session. People who were able to identify the most correct rotations in a given period of time (two 5 minute periods) scored the highest. In this assembly task, the person had to translate his/her mental vision of the assembly (durable trace) and convert it into a series of physical actions that led to the completion of the assembly. In this way, the manipulation of the object on the spatial ability test is analogous to the creation and translation of the durable trace that enabled the subjects to build the assembly from memory. This ability mediated any possible effects from age or distractor condition.

\subsection{Initial Learning of the Assembly}

Older adults were hypothesized to have more problems with the initial learning of the task because of potential deficits in working memory and for decrements in spatial reasoning ability. For this task, however, older adults did not take more trials to initially learn how to build a correct assembly nor did they watch the instructional video more than their younger counterparts (overall). Memory declines in older adults have been shown to exist, but differential declines have also been suggested (West, 1999; Hultsch and Dixon, 1990). Age deficits in working memory have been shown to increase with the complexity of the task (Schieber, 2003). This assembly had nine parts and had a time standard of approximately 19 
seconds; it was meant to replicate similar simple tasks that could be found in the service industry where older adults are often employed. This task may not have been complex enough to generate significant age differences. In addition, the oldest subject in this experiment was sixtyfive. This age was chosen because it represents a traditional retirement age, and the methodology of the experiment included testing working-age people. Often times, older subjects (approaching 75 or 80 years) are included in non-occupational studies on normative aging changes.

\subsection{Goal Oriented Thought}

While older adults didn't take more trials to initially learn the task, they did make more error trials after they had already made at least one correct assembly resulting in significantly more total trials for the oldest group $(69 \%$ of the oldest group made an error trial after they had already constructed the assembly correctly at least one time). The oldest group with the dual distractor condition also took significantly more trials than the middle aged subjects with the dual distractor condition. The adjusted mean number of total trials taken for the oldest group was 8.22 , a $31 \%$ increase over the youngest group.

Why then would older adults, who could initially learn to build the assembly as well as younger adults, make extra mistakes and take more total trials to complete the experiment? To investigate this relationship, the characteristics of the oldest group first as a whole and second by distractor condition were examined. As a entirety, the oldest group had significantly lower SR skills and FIS scores than the youngest group $((\mathrm{F}(2,53)=4.57, \mathrm{p}=0.015)$ for FIS and $(\mathrm{F}(2,53)$ $=6.90, \mathrm{p}=0.002$ ) for $\mathrm{SR}$ ). However, Figure 4 indicates that for the oldest group, the mean 
number of trials did not relate in a mechanistically meaningful way to the distractor condition. For instance, the oldest subjects in the no distractor group took the most trials $(\mathrm{M}=11.05$ trials for the no distractor condition vs. $\mathrm{M}=9.07$ trials for the dual distractor condition).

Mechanistically, subjects in the no distractor condition should not have required more trials than those subjects who were exposed to distractors. A possible reason for these relationships can be found by looking at the characteristics of the oldest subjects who were in the no distractor condition. These subjects had the lowest mean spatial reasoning scores and field independence scores of the entire sample $(M=5.8$ for FIS and $M=5.6$ for SR). Not only were these the lowest means, but the FIS mean score for this subgroup was only $55 \%$ of the overall sample mean and the SR score for this subgroup was only $34 \%$ of the overall sample mean. From a covariate viewpoint, these subjects were not similar to the rest of the sample population.

West (1999) showed that individuals are vulnerable to goal neglect during periods of attentional inefficiency and that instances of goal neglect are more frequent in older than in younger adults when the task demands a lot of attention from the subject. Given the lower SR skills of the oldest group and specifically of the oldest subjects in the no distractor group, the assembly task would have been more attention-demanding for them than for those whose spatial reasoning scores were higher. In fact, although spatial reasoning ability was overall negatively correlated with the number of total trials, a stratified analysis by age shows that only the oldest subjects had a significant and meaningful correlation between SR and number of total trials $(\mathrm{r}=-.494, \mathrm{p} \leq 0.05)$

The assembly that was learned in this task was non-contextual and fairly simple. Recent research on selective attention tasks has been inconclusive as to the performance of older adults on selective attention tasks that have different perceptual loads (Maylor and Lavie, 1998, 
Madden and Langley, 2003). These experiments have tested visual search abilities rather than assembly skills. Questions remain concerning how the complexity of an assembly task would effect the interrelationship between worker age, distractor type and task performance. In addition, since this experiment only studied the initial period of learning where distractor effects could be most disruptive, it is possible the results would be different with much practice.

\subsection{Reinforcement for Learning}

In this experiment subjects were able to watch the video before each trial until they felt that they no longer needed to watch it. Overall, older adults did not watch the instructional video significantly more times than the younger subjects. However, if the complete data were divided between those who made an error trial after a correct trial (disruption of goal oriented thought) and those who did not, older subjects who did not make an error trial after they had made a correct trial watched the video more times than younger subjects who did not make an error trial after a correct trial. Older adults watched the video $23 \%$ longer than the youngest subjects. This suggests that older adults preferred the additional reinforcement obtained by watching the video an extra time or two. It has been shown that older adults often need more practice for computer tasks (Czaja and Lee, 2003). Providing extra reinforcement in the early stages of learning a task could thus make older adults more comfortable with the learning of a task. 


\subsection{Effects of Distractors on Assembly Performance}

Multiple resource theory (MRT) predicts that subject performance will be more disrupted when inputs are along the same channel (either visual with visual or auditory with auditory) than along different channels; Wickens, 1987). In turn, MRT also predicts that time sharing will be more efficient when incoming information is presented and processed along different channels. When information processing approaches capacity in both channels, the information processing speed of the entire system will slow. Wickens (1987) demonstrated that time sharing ability does not differ between age groups (ages 20 to 65 years) for tasks, such as tracking tasks and memory search tasks, that evaluate the speed and capacity of the human information processing system. Although Wickens (1987) used tasks that were both visual and auditory, his subjects were not required to create and manipulate three dimensional objects, and they performed in a timesharing task rather than a task where they were forced to perform in the face of distractors. Older adults have been shown to experience difficulty selectively attending to relevant information when it and the irrelevant information are both presented in the same modality (McDowd, Filion, and Oseas-Kreger, 1991). Older adults have been shown to have difficulty ignoring irrelevant information (Rabbitt, 1965) and irrelevant speech has been shown to disproportionately affect older people (Rouleau and Belleville, 1996). The results of this experiment add to the body of literature in this area by showing that presence of visual distractors slowed the performance times of older adults while the presence of visual and auditory distractors contributed to the disruption of goal oriented thought in the initial stages of learning. Auditory distractors alone were never found to be significant for any age level for any part of the learning. 


\subsection{Aging Effects Related to the Timed Aspect of the Experiment}

The results from this study showed that when older adults were exposed to visual distractors, they had significantly slower trial times than the younger adults who were exposed to visual distractors. The literature regarding psychomotor activities shows that there is a general slowing in information processing (Salthouse and Somberg, 1982 and Scialfa et. al., 1998) and a general slowing for motor mechanisms with increasing age (Welford, 1985 and Salthouse, 1984). Older adults have performed poorer than young adults in tasks that require activity recall and motor activities that require effortful processing (Lichty et al. 1986; Park and Schwarz, 2000; Ratner et. al., 1988; Wishart et. al., 2000). No main effect for age, however, was found for trial time.

An analysis of the plots from Figure 4 for trial time indicates that the mean trial times for the youngest group remained nearly constant across distractor conditions, the mean trial times for the middle-aged group were faster across distractor conditions (subjects actually had faster mean trial times with the addition of distractors) and the mean trial times for the oldest group were slower across distractor conditions (trial times were slower with the addition of distractors). Although it is understandable that the trial times for the youngest group would remain constant across distractor conditions, it remained questionable why the trial times for the middle-aged group would get faster while those for the oldest group would get slower.

Because this experiment tested the earliest part of learning, possible speed accuracy tradeoffs utilized by the subjects could have produced significantly different results for trial time. Subjects were instructed to do the assembly as quick and accurately as possible. Although a 
speed accuracy tradeoff was not seen for all subjects (neither the number of total trials nor the number of error trials were significantly related to trial time (total trials: $r=0.110, p$ value $=$ 0.385 ; error trials: $\mathrm{r}=.210, \mathrm{p}$ value $=.093$ ), the middle aged group in the no distractor condition appeared to use a speed accuracy tradeoff (total trials and trial time: $\mathrm{r}=-.898, \mathrm{p}$ value $=.102$; error trials and trial time: $r=-.997$ and $p$ value $=.003$ ). The use of this strategy would explain the apparently anomalous pattern of mean trial times between distractor conditions for the middle-aged subjects.

In order to determine possible strategies, subjects could have been tested two ways with different instruction sets. For instance, in one experiment subjects could have been asked to perform the task as quickly as possible and for another they could have been asked to perform the task as accurately as possible. In addition, subjects could have been evaluated after the task to determine any conscious strategy that they utilized.

Although the experiment concluded when the subject completed three correct consecutive trials, it appeared that some subjects reached asymptote by the third correct trial and others did not. Because of potentially different strategies between those who reached asymptote and those who didn't, the data set was split. This split proved to be significant and provided two different sets of behaviors: those who could stabilize their motor performance faster and had faster trial times and those who were still improving their performance and had slower times. Those subjects who reached asymptote had 35\% faster trial times and 34\% better spatial reasoning skills than those who did not reach asymptote. The ability to reach asymptote was not significantly related to error trials, total trials, distractor condition, number of times the video was watched, or age of subject. 
CHAPTER 5: CONCLUSIONS, RECOMMENDATIONS, AND SUGGESTIONS FOR FUTURE RESEARCH

\subsection{Conclusions}

This study demonstrated that spatial reasoning ability was a better predictor of task performance than one's age. This was true for both the speeded and the non-speeded aspects of this experiment. Age alone should not be an indicator for one's ability to learn an assembly whether they perform that task in the presence of distractors or not.

The distractors that were chosen for this task were not found to be problematic for the younger or middle aged groups. Visual distractors slowed the trial times for the oldest group while the auditory + visual distractor interrupted goal directed thought for that same group. The disruption of goal oriented thought has been related to attentional deficiencies. Attentional training has been shown to be effective for improving the performance of older adults in motor tasks (Singer, 1991).

Reinforcement necessary in the training phase was evaluated by how many times the instructional video was watched. For those subjects who did not make any error trials after a correct trial, older subjects watched the video more than their younger counterparts even though they did not take more trials to learn the assembly. This may reflect the older adults' more conservative approach to learning whereby they prefer the security of watching the video some additional times. Adding this type of reinforcement to training would require minimal effort, and it is recommended for programs that involve workers over the age of 50 years. 
5.2 Recommendations

Given the results of this study, the following recommendations are suggested:

- Since spatial ability can be improved through training, it is recommended that for job situations that involve the constant learning of spatial tasks, adults over the age of 50 years receive training for their spatial reasoning skills.

- Attentional training programs are recommended for those employees over the age of 50 who work on visuospatial tasks in settings where both auditory and visual distractors are present.

- It is recommended that visual distractors be minimized for employees over the age of 50 years who perform assembly, or other highly visuospatial, timed tasks.

- Added reinforcement for training is recommended for those employees over the age of 50 years who are learning visuospatial tasks.

\subsection{Suggestions for Future Research}

Because of the highly focused nature of this experiment, many aspects of it could be expanded in future research. The endpoint that was studied was the third consecutive correct trial. This point was studied to evaluate the effect of distractors early in the learning curve. This endpoint was chosen because it was thought to represent the period where distractors would be most disruptive to the learning of the task. It would be useful to carry out the studies to a longer endpoint to determine how performance would fluctuate over longer test periods.

In order to better describe the role of visual and auditory distractors, it would be useful to study the effects of individual distractors. For instance, eye tracking has been used to study 
fatigue and attentional changes, and it could be used in this type of study to determine how often the person looked at the visual distractor screen, and how their focus changed with each trial.

It would be useful to determine at which stages of the assembly the subject experienced problems. For instance, did distraction affect the time in which the subject made a mistake? It would be interesting to know what role aging might play in it. Or, perhaps that nature of the assembly itself had an element that appeared non-sequential to the subject and thus induced memory errors. This type of information could be tracked by locating sensors on the blocks or by videoing the subjects.

Finally, in order to limit the scope of this project, distractors were limited to those that could be run from the Visual Basic program. It would be interesting to determine how the location of the distractor (coming from the side or back of the subject) would affect the subject's performance. The addition of a greater variability in distractors over a longer time period might better simulate more dynamic work environments. 
REFERENCES

Birren, J.E. and Schaie, K.W. (1990). Handbook of the Psychology of Aging. New York: Academic Press, Inc.

Bloomberg, M. (1965). Field Independence-Dependence and Susceptibility to Distraction. Perceptual and Motor Skills, 20, 805-813.

Blowers, G.H. (1974). Field Dependence and Distraction in a Simple Psychomotor Task with a Constant Foreperiod. Perceptual and Motor Skills, 39, 1239-1244.

Blowers, G.H. (1976). Field Dependence and Distraction Revisited. Perceptual and Motor Skills, 42, 295-297.

Braddock, D. (1999). Occupational Employment Projections to 2008. Monthly Labor Review, November, 51-77.

Cerella, J., Poon, L.W., and Fozard, J.L. (1981). Mental Rotation and Age Reconsidered. Journal of Gerontology, 36(5), 620-624.

Clarkson-Smith, L and Halpern, D.F. (1983). Can Age-Related Deficits in Spatial Memory be Attenuated Through the Use of Verbal Coding? Experimental Aging Research, 9(3), 179184.

Craik, F. I. M. and Byrd, M. (1982) Aging and Cognitive Deficits: The Role of Attentional Resources. In F.I.M. Craik \& S. Trehub (Eds.), Aging and Cognitive Processes (pp. 191211). New York: Plenum Press.

Czaja, S.J. and Lee, C.C. (2003). The Impact of the Internet on Older Adults. In Charness, N. and Schaie, K.W. (Eds.), Impact of Technology on Successful Aging (pp. 113-133). New York: Springer Publishing Company, Inc. 
Fleishman, E.A. and Reilly, M.E. (1992). Handbook of Human Abilities. California: Consulting Psychologists Press, Inc.

Fullerton, H.N. (1997). Labor Force 2006: Slowing Down and Changing Composition. Monthly Labor Review, November, 23-38.

Fullerton, H. N. (1999). Labor Force Projections to 2008: Steady Growth and Changing Composition. Monthly Labor Review, November, 19-32.

Gaylord, S.A. and Marsh, G.R. (1975). Age Differences in the Speed of a Spatial Cognitive Process. Journal of Gerontology, 30(6), 674-678.

Goldman, J. and Hart Jr., L.W. (1965). Information Theory and Industrial Learning. The Journal of Industrial Engineering, Sept.-Oct., 306-313.

Hancock, W.M. (1967). The Prediction of Learning Rates for Manual Operations. The Journal of Industrial Engineering, Jan., 42-47.

Hasher, L. and Zacks, R.T. (1988). Working Memory, Comprehension, and Aging: A Review and a New View. In G.H. Bower (Ed.), The Psychology of Learning and Motivation (Vol. 22, pp. 193-225). San Diego, CA: Academic Press.

Hultsch, D.F. and Dixon, R.A. (1990). Learning and Memory in Aging. In Birren, J.E. and Schaie, K.W. (Eds.), Handbook of the Psychology of Aging (pp. 258-274). California: Academic Press, Inc.

Jacewicz, M.M. and Hartley, A.A. (1979). Rotation of Mental Images by Young and Old College Students: The Effects of Familiarity. Journal of Gerontology, 34, 396-403.

Karp, S.A. (1963) Field Dependence and Overcoming Embeddedness. Journal of Consulting Psychology, 27(4), 294-302. 
Karp, S.A. (1967). Field Dependence and Occupational Activity in the Aged. Perceptual and Motor Skills, 24, 603-609.

Ketcham, C.J. and Stelmach, G.E. (2001). Age-Related Declines in Motor Control. In Birren, J.E. and Schaie, K.W. (Eds.), Handbook of the Psychology of Aging (pp. 313-348). CA: Academic Press.

Lichty, W., Kausler, D.H., and Martinez, D.R. (1986). Adult Age Differences in Memory for Motor Versus Cognitive Activities. Experimental Aging Research, 12(4), 227-230.

Madden, D.J. and Langley, L.K. (2003). Age-Related Changes in Selective Attention and Perceptual Load During Visual Search. Psychology and Aging, 18(1), 54-67.

Makkar, M., Malhotra, D., and Jerath, J.M. (1999). Perceptual Strategies in Short-Term Memory. Studia Psychologica, 41, 231-236.

Maylor, E.A. and Lavie, N. (1998). The Influence of Perceptual Load on Age Differences in Selective Attention. Psychology and Aging, 13(4), 563-573.

McDowd, J.M., Filion, D.L. and Oseas-Kreger, D.M. (1991). Inhibitory Deficits in Selective Attention and Aging. Poster Session presented at the annual meeting of the American Psychological Society, Washington, D.C.

Mykityshyn, A.L., Fisk, A.D. and Rogers, W.A. (2002). Learning to Use a Home Medical Device: Mediating Age-Related Differences with Training. Human Factors, 44(3), 354364.

Neter, J., Wasserman, W. and Kutner, M.H. (1990). Applied Linear Statistical Models. Massachusetts: Richard D. Irwin, Inc.

Panek, P.E. (1985). Age Differences in Field Dependence/Independence. Experimental Aging Research, 11(2), 97-99. 
Park, D. and Schwarz, N. (2000). Cognitive Aging: A Primer. Philadelphia: Taylor and Francis, Psychology Press.

Prabhu, G.V., Helander, M.G. and Shalin, V.L. (1995). Effect of Product Structure on Manual Assembly Performance. The International Journal of Human Factors in Manufacturing, $\underline{5(2)}, 149-161$.

Rabbit, P. A. (1965). An Age Decrement in the Ability to Ignore Irrelevant Information. Journal of Gerontology, 20, 233-238.

Ratner, H.H., Padgett, R.J., and Bushey, N. (1988). Old and Young Adults’ Recall of Events. Developmental Psychology, 25(5), 664-671.

Rogers, W.A. and Fisk, A.D. (2001). Understanding the Role of Attention in Cognitive Aging Research. In Birren, J.E. and Schaie, K.W. (Eds.), Handbook of the Psychology of Aging (pp. 267-287).CA: Academic Press.

Rouleau, N. and Belleville, S. (1996). Irrelevant Speech Effect in Aging: An Assessment of Inhibitory Processes in Working Memory. Journal of Gerontology: Psychological Sciences, 51B(6), P356-P363.

Salthouse, T. A. (1984). Effects of Age and Skill in Typing. Journal of Experimental Psychology: General, 113, 345-371.

Salthouse, T.A., Babcock, R.L., Skovronek, E., Mitchell, D.R.D., and Palmon, R. (1990). Age and Experience Effects in Spatial Visualization. Developmental Psychology, 26(1), 128136.

Salthouse, T.A. and Somberg, B.L. (1982). Skilled Performance: Effects of Adult Age and Experience on Elementary Processes. Journal of Experimental Psychology: General, 111(2), 176-207. 
Schieber, F. (2003). Human Factors and Aging: Identifying and Compensating for Agerelated Deficits in Sensory and Cognitive Function. In Charness, N. and Schaie, K.W (Eds.), Impact of Technology on Successful Aging (pp. 42-84). New York: Springer Publishing Company, Inc.

Schwartz, D.W. and Karp, S.A. (1967). Field Dependence in a Geriatric Population. Perceptual and Motor Skills, 24, 495-504.

Scialfa, C.T., Esau, S.P. and Joffe, K.M. (1998). Age, Target-Distractor Similarity, and Visual Search. Experimental Aging Research, 24, 337-358.

Shalin, V.L., Prabhu, G.V. and Helander, M.G. (1996). A Cognitive Perspective on Manual Assembly. Ergonomics, 39(1), 108-127.

Shepard, R.N. and Metzler, J. (1971). Mental Rotation of Three-Dimensional Objects. $\underline{\text { Science, }}$ $171,701-703$.

Singer, R.N., Caurcaugh, J.H., Murphey, M., Chen, D. and Lidor, R. (1991). Attentional Control, Distractors, and Motor Performance. Human Performance, 4(1), 55-69.

Vandenberg, S.G. and Kuse, A.R. (1978). Mental Rotations, A Group Test of Three-Dimensional Spatial Visualization. Perceptual and Motor Skills, 47, 599-604.

Welford, A.T. (1962). Changes in Performance Time with Age: A Correction and Methodological Note. Ergonomics, 5(4), 581-582.

Welford, A.T. (1985). Changes of Performance with Age: An Overview. In N. Charness (Ed.), Aging and Human Performance (pp. 333-369). New York: John Wiley \& Sons.

West, R. (1999). Visual Distraction, Working Memory, and Aging. Memory \& Cognition, 27(6), 1064-1072. 
Wickens, C.D., Braune, R. and Stokes, A. (1987). Age Differences in the Speed and Capacity of Information Processing: 1. A Dual-Task Approach. Psychology and Aging, 2(1), 7078.

Wickens, C.D. (1992) Engineering Psychology and Human Performance, $2^{\text {nd }}$. Ed. New York: Harper Collins Publishers, Inc.

Wishart, L.R., Lee, T.D., Murdoch, J.E. and Hodges, N.J. (2000). Effects of Aging on Automatic and Effortful Processes in Bimanual Coordination. Journal of Gerontology: Psychological Sciences, 55B(2), P85-P94.

Witkin, H.A. and Goodenough, D.R. (1981). Cognitive Styles: Essence and Origins, Field Dependence and Field Independence. New York: International Universities Press, Inc.

Witkin, , H.A., Oltman, P.K., Raskin, E., and Karp, S.A. (1971). Manual for the Embedded Figures Test. California: Consulting Psychologists Press, Inc.

Zacks, R. and Hasher, L. (1997). Cognitive Gerontology and Attentional Inhibition: A Reply to Burke and McDowd. Journal of Gerontology: Psychological Sciences, 52B(6), 274-283. 


\section{APPENDIX A-Transcription of Auditory Distractors}

Sound File 1

Hey, did you see the weather today? It's, ah, really rainy. We are supposed to get you know some sunny weather by the end of the week. I think probably we'll get it maybe on Friday. Pretty soon the daylight going to be changing. I just can't believe it. At least we're not going to get that hurricane they talked about. That would have been really bad. I can't even imagine. But, if we get some sun, some 70 degree weather in October, you can't beat that. I definitely don't want any snow, that would be too much (11 sentences, 98 words).

\section{Sound File 2}

Hey, how's it going? Did you get that new order? Um, the order is going to be the blues and the reds--the blue and the red in alternating order. There's going to be six rows and blue and then a break, and then six rows of red, and then back and forth. Um, We'll work on that assembly today. We're going to work on the sequential yellow and green tomorrow and then followed by the blue and yellow and then the red and green. This assembly should be done by the end of the week ( 7 sentences, 96 words).

\section{Sound File 3}

Did you see that new movie on the TV last night? It was so funny. It was on at 8 o'clock. Um, luckily I got home from work in time to see it. But, it's a mystery, it's on. It's really funny--it has this compulsive person in it. I tend to like comedies, too, you might watch those comedies on Thursday nights. Thursday night is always a good night for TV. I'm glad I 
definitely don't work the three to eleven shift on Thursday night. I'd be missing out on everything (10 sentences, 92 words).

\section{Sound File 4}

Hey, there's an order coming in outside. Um, the truck is going to be here by four o'clock. We should be able to get it unloaded by five. Um, those are the items that we're going to use for the assembly, the sequential assembly next week--the blue and the yellow. Um, there's another truck coming in tomorrow. That's going to be for two weeks from now. I just can't believe that we're scheduling this far out. But, we have this week the blue and the red, next week the red and the blue, and then we're going to follow on a different cycle ( 8 sentences, 104 words). 
APPENDIX B - Code for Visual Basic Program

Code for Form Dissertaton

Private strName As String

Private iAge As Integer

Private dtStart As Double

Private dtEnd As Double

Private dtResult As Double

Public iTask As Integer

Public iType As Integer

Private iGroup As Integer

Public bKeepPlaying As Boolean

Public bLoopMode As Boolean

Private rsTests As New ADODB.Recordset

Private Type udtTrial

strName As String

iAge As Integer

iTask As Integer

iType As Integer

iGroup As Integer

dblResult As Double

End Type

Private arrTrials() As udtTrial

Private Sub form_load()

frmDissertation. . $o p=0$

frmDissertation.Left $=0$

frmDissertation. Width $=17500$

frmDissertation. Height $=15000$

bLoopMode $=$ False

ReDim Preserve arrTrials $(0)$

For $\mathrm{i}=1$ To 4

Cboexperimenttype.AddItem "Condition " \& i

Next $\mathrm{i}$

For $\mathrm{i}=1$ To 2

cboTask.AddItem "Task " \& i

Next i

End Sub

Private Sub Command1_Click()

bKeepPlaying $=$ False

'MediaPlayer1.Stop

' If iType $<>1$ Then

frmInstructions.MediaPlayer1.Stop

' End If 


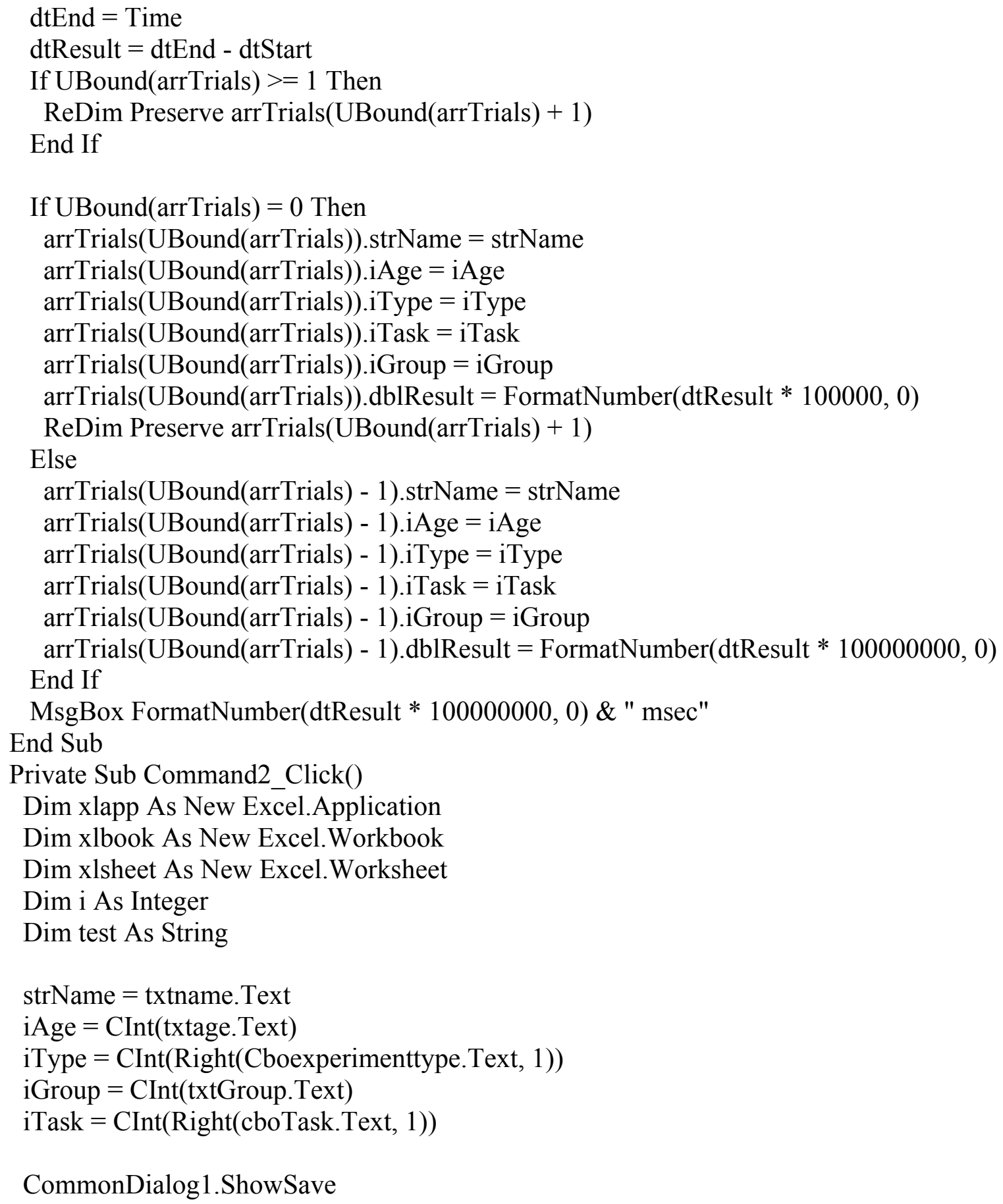


$\mathrm{i}=1$

While xlsheet.Cells(i, 1).Value $<>$ "'"

test $=$ xlsheet.Cells $(i, 1)$.Value

$\mathrm{i}=\mathrm{i}+1$

Wend

If $i=1$ Then

xlsheet.Cells $(i, 1)$. Value $=$ "Name"

xlsheet.Cells $(i, 2)$. Value $=$ "Condition"

xlsheet.Cells(i, 3). Value $=$ "Task"

xlsheet.Cells(i, 4).Value = "Age"

xlsheet.Cells(i, 5).Value = "Group"

xlsheet.Cells $(i, 6)$. Value $=$ "Cycle Time"

$\mathrm{i}=\mathrm{i}+1$

End If

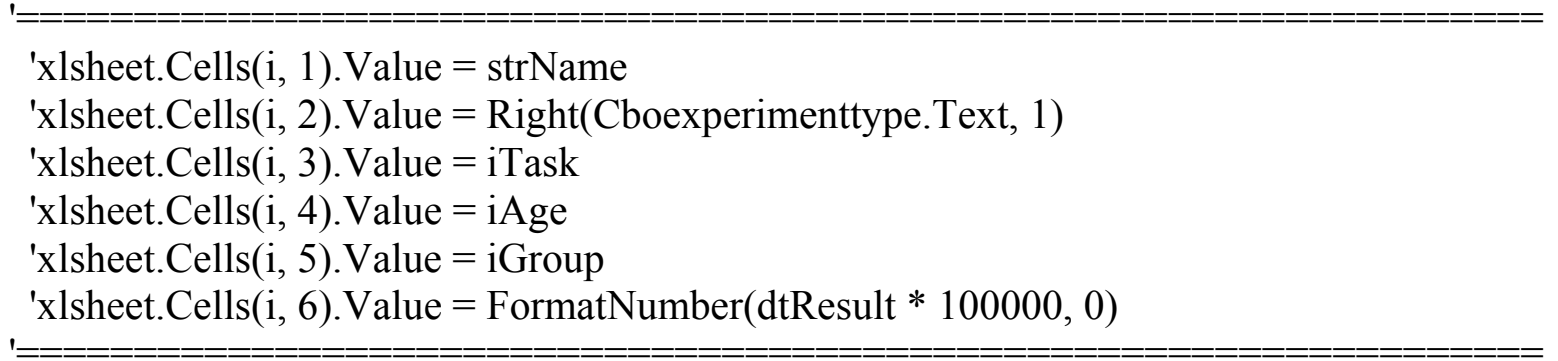

For $\mathrm{j}=$ LBound(arrTrials) To UBound(arrTrials) - 1

xlsheet.Cells $(i, 1)$.Value $=\operatorname{arrTrials}(j)$.strName

xlsheet.Cells $(i, 2)$.Value $=\operatorname{arrTrials}(j)$. iType

xlsheet.Cells $(i, 3)$. Value $=\operatorname{arrTrials}(j) . i$ Task

xlsheet.Cells $(i, 4)$.Value $=\operatorname{arrTrials}(j)$. Age

xlsheet.Cells $(i, 5)$.Value $=\operatorname{arrTrials}(j)$. iGroup

xlsheet.Cells $(i, 6)$. Value $=\operatorname{arrTrials}(j) \cdot d b l R e s u l t$

$\mathrm{i}=\mathrm{i}+1$

Next j

'Set arrTrials $=$ Nothing

ReDim Preserve arrTrials $(0)$

xlbook.SaveAs CommonDialog1.FileName

xlbook.Close

xlapp.Quit

End Sub

Private Sub cmdinstructions_Click()

If txtname.Text = "" Or txtage.Text = "" Then

MsgBox "Please enter name and age"

Else

strName $=$ txtname. Text

iAge $=$ CInt (txtage. Text) 
iType $=\operatorname{CInt}(\operatorname{Right}($ Cboexperimenttype.Text, 1) $)$

iGroup $=$ CInt $($ txtGroup. Text $)$

iTask $=$ CInt $($ Right $($ cboTask.Text, 1))

frmInstructions. Show

' frmInstructions.MediaPlayer1.FileName = "C: $\backslash$ users $\backslash$ QuickCam $\backslash A l b u m \backslash$ Videos $\backslash$ easy.avi"

'MediaPlayer1.Play

End If

End Sub

Private Sub cmdstart_Click()

If txtname.Text = "" Or txtage. Text $=$ "" Then

MsgBox "Please enter name and age"

Else

$\mathrm{dtStart}=$ Time

strName $=$ txtname. Text

iAge $=$ CInt (txtage.Text)

iType $=\operatorname{CInt}(\operatorname{Right}($ Cboexperimenttype.Text, 1) $)$

iGroup $=$ CInt(txtGroup.Text)

iTask $=$ CInt $($ Right $($ cboTask.Text, 1))

Select Case iType

Case 1

bLoopMode $=$ True

bKeepPlaying $=$ True

frmInstructions. Show

Case 2

'looped audio file

'MMControl1.FileName = "C: $\backslash$ WINDOWS $\backslash$ Desktop $\backslash$ Distraction $\backslash$ Sound1.wav"

'MMControl1.Command = "Open"

'Call MMControl1_PlayClick(0)

'Call Playsound("C: $\backslash$ WINDOWS $\backslash$ Desktop $\backslash$ Distraction $\backslash$ Sound1.wav")

bLoopMode $=$ True

bKeepPlaying $=$ True

frmInstructions. Show

'frmInstructions.MediaPlayer1.Play

Case 3

'looped video file

bLoopMode $=$ True

bKeepPlaying $=$ True

frmInstructions. Show

'frmInstructions.MediaPlayer1.FileName = "C: \users \QuickCam $\backslash$ Album $\backslash$ Videos $\backslash$ Test1 .avi"

'frmInstructions.MediaPlayer1.Visible = False

Case 4

'looped audio and video

bLoopMode $=$ True 
bKeepPlaying $=$ True

frmInstructions. Show

'frmInstructions.MediaPlayer1.FileName = "C: \users $\backslash$ QuickCam $\backslash$ Album $\backslash$ Videos $\backslash$ Test1.avi"

'frmInstructions.MediaPlayer1.Visible = False

End Select

End If

End Sub

Private Sub MediaPlayer1_PlayStateChange(ByVal OldState As Long, ByVal NewState As

Long)

Dim lold As Long

Dim lnew As Long

lold $=$ OldState

lnew $=$ NewState

If OldState $=2$ And frmDissertation.bKeepPlaying $=$ False Then

Unload frmInstructions

End If

End Sub

Private Sub MediaPlayer1_EndOfStream(ByVal Result As Long)

If bKeepPlaying $=$ True Then

MediaPlayer1.Play

End If

End Sub

Private Sub form_Unload(Cancel As Integer)

'aadsf

End Sub

Code for Form Instructions

Private Sub form_load()

Dim MyValue, counter, Result 'kaustubh

frmInstructions. Top $=$ frmDissertation.Top

frmInstructions.Left $=$ frmDissertation.Left

frmDissertation. Width $=17500$

frmDissertation. Height $=15000$

frmInstructions. Width $=15000$

frmInstructions. Height $=10500$

If frmDissertation.bLoopMode $=$ False Then

'----------instructions videos-

If frmDissertation.iTask $=1$ Then

MediaPlayer1.FileName $=$ "C: $\mid$ Documents and

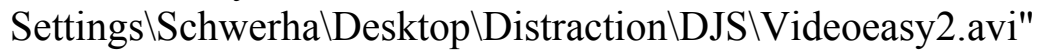


MediaPlayer1. Visible $=$ True

ElseIf frmDissertation.iTask $=2$ Then

MediaPlayer1.FileName $=$ "C: $\mid$ Documents and

Settings $\backslash$ Schwerha $\backslash$ Desktop $\backslash$ Distraction $\backslash D J S \backslash V i d e o d i f f i c u l t . a v i "$

MediaPlayer1. Visible $=$ True

End If

Else

'----------looped experiment videos

If frmDissertation.iType $=1$ Then

MediaPlayer1.Stop

MediaPlayer1.FileName $=" C: \backslash$ Documents and

Settings $\backslash$ Schwerha $\backslash$ Desktop $\backslash$ Distraction $\backslash D J S \backslash$ pic2video.avi"

MediaPlayer1. Visible $=$ True

MediaPlayer2.FileName $=$ "C: $\backslash$ Documents and

Settings $\backslash$ Schwerha $\backslash$ Desktop $\backslash$ Distraction $\backslash D J S \backslash p i c 2 v i d e o . a v i "$

frmInstructions. Height $=10500$

frmInstructions. Width $=15000$

ElseIf frmDissertation.iType $=2$ Then

Randomize

counter $=1$

'Do Until counter $=1$

MyValue $=\operatorname{Int}((4 *$ Rnd $)+1)$

If MyValue $=1$ Then

MediaPlayer1.FileName $=" \mathrm{C}: \backslash$ Documents and

Settings $\backslash$ Schwerha $\backslash$ Desktop $\backslash$ Distraction $\backslash D J S \backslash$ sound3.wav"

MediaPlayer1. Visible $=$ False

ElseIf MyValue $=2$ Then

MediaPlayer1.FileName $=$ "C: $\backslash$ Documents and

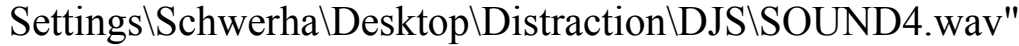

MediaPlayer1. Visible $=$ False

ElseIf MyValue $=3$ Then

MediaPlayer1.FileName $=" \mathrm{C}: \backslash$ Documents and

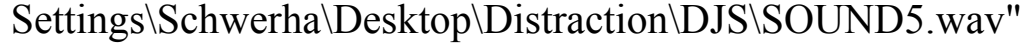

MediaPlayer1.Visible $=$ False

ElseIf MyValue $=4$ Then

MediaPlayer1.FileName = "C: $\backslash$ Documents and

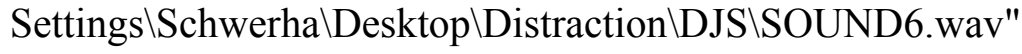

MediaPlayer1 Visible $=$ False

End If

'Loop 
MediaPlayer2.FileName $=" C: \mid$ Documents and

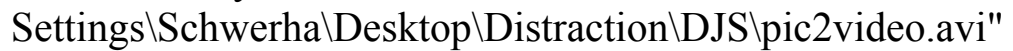

MediaPlayer2. Visible $=$ True

frmInstructions. Height $=10500$

frmInstructions. Width $=15000$

ElseIf frmDissertation.iType $=3$ Then

MediaPlayer1. Visible $=$ True

MediaPlayer1.FileName $=$ "C: $\backslash$ Documents and

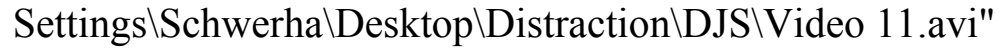

ElseIf frmDissertation.iType $=4$ Then

MediaPlayer2. Visible $=$ True

MediaPlayer2.FileName $=" \mathrm{C}: \mid$ Documents and

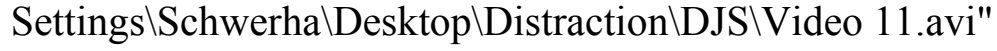

MediaPlayer2.Play

Randomize

counter $=1$

'Do Until counter $=1$

MyValue $=\operatorname{Int}((4 *$ Rnd $)+1)$

If MyValue $=1$ Then

MediaPlayer1.FileName = "C: $\backslash$ Documents and

Settings $\backslash$ Schwerha $\backslash$ Desktop $\backslash$ Distraction\DJS $\backslash$ sound3.wav"

MediaPlayer1.Visible $=$ False

ElseIf MyValue $=2$ Then

MediaPlayer1.FileName $=" C: \backslash$ Documents and

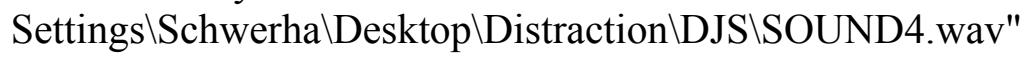

MediaPlayer1. Visible $=$ False

ElseIf MyValue = 3 Then

MediaPlayer1.FileName $=" \mathrm{C}: \mid$ Documents and

Settings $\backslash$ Schwerha $\backslash$ Desktop $\backslash$ Distraction $\backslash D J S \backslash S O U N D 5 . w a v "$

MediaPlayer1. Visible $=$ False

ElseIf MyValue $=4$ Then

MediaPlayer1.FileName $=" \mathrm{C}: \mid$ Documents and

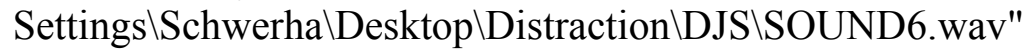

MediaPlayer1. Visible $=$ False

End If

End If

End If

MediaPlayer1.Play

'MediaPlayer2.Play

End Sub 
Private Sub dothis()

If frmDissertation.iType $=1$ Then

MediaPlayer1.FileName $=$ "C: $\mid$ Documents and

Settings $\backslash$ Schwerha $\backslash$ Desktop $\backslash$ Distraction $\backslash D J S \backslash$ pic2video.avi"

MediaPlayer1. Visible $=$ True

MediaPlayer2.FileName $=" \mathrm{C}: \backslash$ Documents and

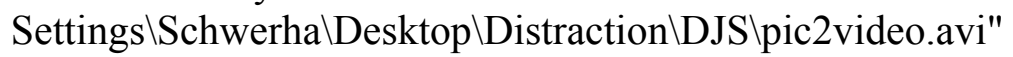

' MediaPlayer2. Visible $=$ True

'MediaPlayer2.Play

frmInstructions. Height $=10500$

frmInstructions. Width $=15000$

ElseIf frmDissertation.iType $=2$ Then

Randomize

counter $=1$

'Do Until counter $=1$

MyValue $=\operatorname{Int}((4 *$ Rnd $)+1)$

If MyValue $=1$ Then

MediaPlayer1.FileName $=$ "C: $\mid$ Documents and

Settings $\backslash$ Schwerha $\backslash$ Desktop $\backslash$ Distraction $\backslash D J S \backslash$ sound3.wav"

MediaPlayer1.Visible $=$ False

ElseIf MyValue $=2$ Then

MediaPlayer1.FileName $=$ "C: $\backslash$ Documents and

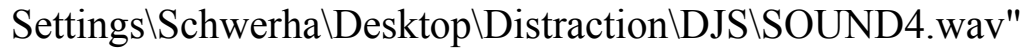

MediaPlayer1.Visible $=$ False

ElseIf MyValue $=3$ Then

MediaPlayer1.FileName $=$ "C: $\backslash$ Documents and

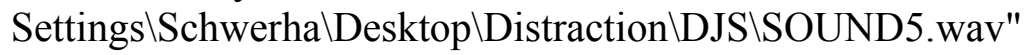

MediaPlayer1.Visible $=$ False

ElseIf MyValue $=4$ Then

MediaPlayer1.FileName $=" \mathrm{C}: \mid$ Documents and

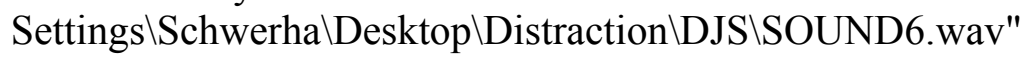

MediaPlayer1.Visible $=$ False

End If

ElseIf frmDissertation.iType $=3$ Then

MediaPlayer1. Visible $=$ True

MediaPlayer1.FileName $=" \mathrm{C}: \mid$ Documents and

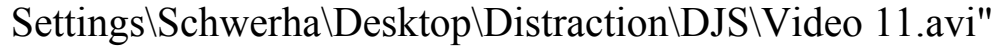

ElseIf frmDissertation.iType $=4$ Then

MediaPlayer2. Visible $=$ True

MediaPlayer2.FileName = "C: $\backslash$ Documents and

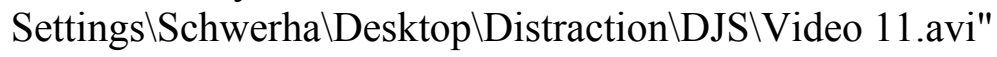

MediaPlayer2.Play

Randomize

counter $=1$ 
'Do Until counter $=1$

MyValue $=\operatorname{Int}((4 *$ Rnd $)+1)$

If MyValue $=1$ Then

MediaPlayer1.FileName $=$ "C: $\backslash$ Documents and

Settings $\backslash$ Schwerha $\backslash$ Desktop $\backslash$ Distraction $\backslash D J S \backslash$ sound3.wav"

MediaPlayer1. Visible $=$ False

ElseIf MyValue $=2$ Then

MediaPlayer1.FileName $=$ "C: $\backslash$ Documents and

Settings $\backslash$ Schwerha $\backslash$ Desktop $\backslash$ Distraction $\backslash D J S \backslash S O U N D 4 . w a v "$

MediaPlayer1. Visible $=$ False

ElseIf MyValue $=3$ Then

MediaPlayer1.FileName $=" \mathrm{C}: \backslash$ Documents and

Settings $\backslash$ Schwerha $\backslash$ Desktop $\backslash$ Distraction $\backslash D J S \backslash S O U N D 5 . w a v "$

MediaPlayer1. Visible $=$ False

ElseIf MyValue $=4$ Then

MediaPlayer1.FileName $=" \mathrm{C}: \backslash$ Documents and

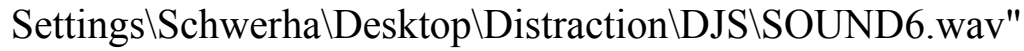

MediaPlayer1. Visible $=$ False

End If

End If

MediaPlayer1.Play

End Sub

Private Sub MediaPlayer1_EndOfStream(ByVal Result As Long)

If frmDissertation.bKeepPlaying $=$ True Then

'MediaPlayer1.Play

dothis

Else

Unload frmInstructions

frmDissertation.bLoopMode $=$ False

End If

End Sub

Private Sub MediaPlayer1_PlayStateChange(ByVal OldState As Long, ByVal NewState As

Long)

Dim lold As Long

Dim lnew As Long

lold $=$ OldState

lnew $=$ NewState

If OldState $=2$ And frmDissertation.bKeepPlaying $=$ False Then

frmDissertation.bLoopMode $=$ False

Unload frmInstructions

End If 
End Sub 
APPENDIX C-Dataset

\begin{tabular}{|c|c|c|c|c|c|c|c|c|c|c|c|c|}
\hline Sub & Video & Errors & Trials & Error/A & Time & Age & Audio & Visual & Gen & FDI & $\overline{S R}$ & YFE \\
\hline 2 & 5 & 4 & 7 & 1 & 21.99 & 24 & 1 & 1 & 2 & 12 & 10 & 16 \\
\hline 3 & 2 & 0 & 3 & 1 & 27.78 & 20 & 1 & 1 & 1 & 15 & 23 & 16 \\
\hline 5 & 5 & 4 & 7 & 1 & 33.56 & 24 & 1 & 1 & 1 & 9 & 10 & 16 \\
\hline 8 & 3 & 3 & 6 & 1 & 19.67 & 27 & 1 & 1 & 1 & 14 & 34 & 18 \\
\hline 10 & 3 & 2 & 5 & 1 & 18.52 & 23 & 1 & 1 & 2 & 16 & 26 & 17 \\
\hline 12 & 5 & 3 & 6 & 1 & 26.62 & 24 & 2 & 1 & 2 & 16 & 22 & 17 \\
\hline 13 & 2 & 1 & 4 & 1 & 23.15 & 23 & 2 & 1 & 2 & 18 & 32 & 17 \\
\hline 16 & 6 & 4 & 7 & 1 & 28.94 & 24 & 2 & 1 & 2 & 14 & 24 & 17 \\
\hline 19 & 3 & 3 & 6 & 1 & 19.67 & 22 & 2 & 1 & 2 & 16 & 27 & 16 \\
\hline 20 & 3 & 2 & 5 & 1 & 25.46 & 20 & 2 & 1 & 1 & 15 & 21 & 15 \\
\hline 141 & 6 & 3 & 6 & 1 & 26.62 & 24 & 2 & 1 & 2 & 5 & 12 & 16 \\
\hline 143 & 3 & 2 & 5 & 1 & 21.99 & 23 & 2 & 1 & 1 & 17 & 30 & 17 \\
\hline 21 & 4 & 3 & 9 & 2 & 23.15 & 22 & 1 & 2 & 1 & 9 & 18 & 16 \\
\hline 26 & 4 & 3 & 6 & 1 & 21.99 & 23 & 1 & 2 & 1 & 16 & 8 & 17 \\
\hline 27 & 6 & 4 & 7 & 1 & 25.46 & 26 & 1 & 2 & 2 & 16 & 14 & 19 \\
\hline 28 & 5 & 3 & 6 & 1 & 21.99 & 26 & 1 & 2 & 1 & 12 & 8 & 19 \\
\hline 29 & 3 & 2 & 5 & 1 & 15.05 & 23 & 1 & 2 & 2 & 17 & 40 & 17 \\
\hline 32 & 5 & 2 & 5 & 1 & 26.62 & 20 & 2 & 2 & 1 & 14 & 14 & 16 \\
\hline 35 & 5 & 3 & 8 & 2 & 25.46 & 23 & 2 & 2 & 2 & 5 & 24 & 17 \\
\hline 40 & 3 & 2 & 5 & 1 & 15.05 & 21 & 2 & 2 & 2 & 10 & 32 & 15 \\
\hline 142 & 6 & 4 & 7 & 1 & 35.88 & 25 & 2 & 2 & 1 & 5 & 15 & 17 \\
\hline 140 & 3 & 1 & 13 & 2 & 18.52 & 26 & 2 & 2 & 2 & 16 & 36 & 16.5 \\
\hline 42 & 5 & 2 & 7 & 2 & 35.88 & 48 & 1 & 1 & 1 & 9 & 33 & 12 \\
\hline 45 & 4 & 2 & 5 & 1 & 35.88 & 40 & 1 & 1 & 1 & 1 & 12 & 16 \\
\hline 47 & 3 & 2 & 5 & 1 & 34.72 & 44 & 1 & 1 & 2 & 18 & 20 & 19 \\
\hline 48 & 6 & 7 & 10 & 1 & 21.99 & 49 & 1 & 1 & 1 & 12 & 22 & 17 \\
\hline 51 & 8 & 4 & 9 & 2 & 29.91 & 49 & 2 & 1 & 1 & 13 & 9 & 18 \\
\hline 52 & 4 & 1 & 4 & 1 & 43.98 & 42 & 2 & 1 & 1 & 14 & 7 & 18 \\
\hline 53 & 5 & 2 & 5 & 1 & 37.04 & 49 & 2 & 1 & 1 & 4 & 18 & 16 \\
\hline 54 & 3 & 2 & 5 & 1 & 21.99 & 46 & 2 & 1 & 1 & 2 & 21 & 12 \\
\hline 55 & 3 & 2 & 5 & 1 & 21.99 & 44 & 2 & 1 & 2 & 16 & 31 & 16 \\
\hline 56 & 4 & 2 & 5 & 1 & 21.99 & 40 & 2 & 1 & 1 & 8 & 17 & 16 \\
\hline 57 & 3 & 3 & 6 & 1 & 35.88 & 49 & 2 & 1 & 2 & 2 & 6 & 14 \\
\hline 61 & 3 & 2 & 5 & 1 & 20.83 & 46 & 1 & 2 & 1 & 8 & 15 & 14 \\
\hline 62 & 10 & 6 & 13 & 2 & 25.46 & 49 & 1 & 2 & 1 & 0 & 12 & 17.5 \\
\hline 64 & 8 & 7 & 13 & 2 & 26.62 & 40 & 1 & 2 & 2 & 7 & 4 & 19 \\
\hline 65 & 4 & 4 & 7 & 1 & 20.83 & 49 & 1 & 2 & 1 & 12 & 17 & 16 \\
\hline 66 & 3 & 1 & 4 & 1 & 30.09 & 48 & 1 & 2 & 1 & 17 & 18 & 14 \\
\hline 72 & 4 & 3 & 6 & 1 & 33.56 & 40 & 2 & 2 & 2 & 9 & 5 & 18 \\
\hline 74 & 4 & 2 & 5 & 1 & 24.31 & 41 & 2 & 2 & 1 & 7 & 8 & 18 \\
\hline 75 & 7 & 5 & 8 & 1 & 24.31 & 41 & 2 & 2 & 1 & 15 & 14 & 18 \\
\hline 76 & 3 & 2 & 5 & 1 & 20.83 & 43 & 2 & 2 & 1 & 15 & 20 & 16 \\
\hline 77 & 3 & 1 & 4 & 1 & 18.52 & 45 & 2 & 2 & 1 & 9 & 26 & 19 \\
\hline 81 & 12 & 10 & 16 & 2 & 26.62 & 52 & 1 & 1 & 1 & 10 & 4 & 14 \\
\hline 82 & 4 & 1 & 7 & 2 & 27.78 & 51 & 1 & 1 & 1 & 5 & 8 & 13 \\
\hline 83 & 7 & 4 & 9 & 2 & 25.46 & 52 & 1 & 1 & 2 & 5 & 4 & 13 \\
\hline
\end{tabular}




\begin{tabular}{rrrrrrrrrrrrr}
\hline Sub & Video & Errors & Trials & Error/A & Time & Age & Audio & Visual & Gen & FDI & SR & YFE \\
\hline 84 & 3 & 2 & 7 & 2 & 35.88 & 65 & 1 & 1 & 1 & 3 & 3 & 12 \\
\hline 85 & 4 & 3 & 13 & 2 & 25.46 & 54 & 1 & 1 & 1 & 6 & 9 & 16 \\
\hline 91 & 6 & 4 & 7 & 1 & 47.45 & 60 & 2 & 1 & 1 & 2 & 6 & 16 \\
\hline 92 & 5 & 4 & 7 & 1 & 24.31 & 60 & 2 & 1 & 1 & 7 & 6 & 14 \\
\hline 93 & 4 & 3 & 9 & 2 & 21.99 & 57 & 2 & 1 & 2 & 16 & 26 & 17 \\
\hline 94 & 6 & 4 & 7 & 1 & 30.09 & 53 & 2 & 1 & 1 & 12 & 4 & 16 \\
\hline 95 & 2 & 1 & 4 & 1 & 18.52 & 52 & 2 & 1 & 1 & 16 & 28 & 12 \\
\hline 96 & 5 & 4 & 7 & 1 & 27.78 & 51 & 2 & 1 & 2 & 6 & 6 & 20 \\
\hline 101 & 7 & 5 & 8 & 1 & 27.78 & 61 & 1 & 2 & 1 & 13 & 18 & 18 \\
\hline 102 & 5 & 3 & 6 & 1 & 25.46 & 56 & 1 & 2 & 1 & 10 & 21 & 18 \\
\hline 103 & 5 & 2 & 5 & 1 & 38.19 & 64 & 1 & 2 & 1 & 14 & 20 & 20 \\
\hline 104 & 10 & 6 & 11 & 2 & 27.78 & 65 & 1 & 2 & 1 & 4 & 7 & 18 \\
\hline 106 & 5 & 2 & 7 & 2 & 24.31 & 56 & 1 & 2 & 2 & 13 & 13 & 20 \\
\hline 108 & 5 & 2 & 5 & 1 & 32.41 & 53 & 1 & 2 & 2 & 7 & 20 & 18 \\
\hline 111 & 7 & 6 & 9 & 1 & 38.19 & 54 & 2 & 2 & 1 & 15 & 19 & 13 \\
\hline 112 & 9 & 7 & 13 & 2 & 35.88 & 63 & 2 & 2 & 1 & 7 & 6 & 18 \\
\hline 113 & 4 & 3 & 6 & 1 & 38.19 & 64 & 2 & 2 & 2 & 8 & 16 & 12 \\
\hline 114 & 4 & 2 & 5 & 1 & 28.94 & 51 & 2 & 2 & 2 & 11 & 18 & 16 \\
\hline 115 & 11 & 8 & 11 & 1 & 46.29 & 53 & 2 & 2 & 1 & 6 & 6 & 18 \\
\hline & & & & & & & & & & &
\end{tabular}

Note: $\mathrm{Sub}=$ subject, Video $=$ number of times the video was watched, Errors $=$ number of error trials before a correct trial, Trials $=$ number of trials needed to complete the experiment, Error/A $=$ presence of an error trial after a correct one $(1$ is no, 2 is yes $)$, Time $=$ time for third consecutive correct trial in seconds, Age $=$ age of subject, Audior $=$ presence of an auditory distractor $(1=$ no auditory distractor, $2=$ presence of an auditory distractor $)$, Visual $=$ presence of a visual distractor $(1=$ no visual distractor and $2=$ presence of a visual distractor $)$, Gen $=$ Gender of subject $(1=$ female, $2=$ male $)$, FDI $=$ Field Dependence Score, $S R=$ Spatial Reasoning Score, YFE $=$ Years of Formal Education. 
APPENDIX D_-Means for Error Trials Before a Correct Trial

\begin{tabular}{llllrrr}
\hline $\begin{array}{l}\text { Age Group of } \\
\text { Subject }\end{array}$ & $\begin{array}{l}\text { Distractor } \\
\text { Auditory }\end{array}$ & $\begin{array}{l}\text { Distractor } \\
\text { Visual }\end{array}$ & Mean & $\begin{array}{c}\text { Std. } \\
\text { Error }\end{array}$ & \multicolumn{2}{c}{$\begin{array}{r}\text { 95\% Confidence } \\
\text { Interval }\end{array}$} \\
\hline & & & & & $\begin{array}{c}\text { Lower } \\
\text { Bound }\end{array}$ & $\begin{array}{r}\text { Upper } \\
\text { Bound }\end{array}$ \\
Age 18-28 & 1 & 1 & $2.879(\mathrm{a})$ & .771 & 1.330 & 4.428 \\
& & 2 & $2.853(\mathrm{a})$ & .791 & 1.265 & 4.441 \\
& 2 & 1 & $3.156(\mathrm{a})$ & .681 & 1.789 & 4.523 \\
& & 2 & $2.920(\mathrm{a})$ & .799 & 1.315 & 4.526 \\
Age 40-50 & 1 & 1 & $3.673(\mathrm{a})$ & .863 & 1.940 & 5.407 \\
& & 2 & $3.781(\mathrm{a})$ & .766 & 2.244 & 5.319 \\
& 2 & 1 & $2.313(\mathrm{a})$ & .652 & 1.004 & 3.623 \\
Age 51-65 & \multirow{2}{*}{1} & 2 & $2.125(\mathrm{a})$ & .779 & .560 & 3.690 \\
& & 1 & $3.783(\mathrm{a})$ & .929 & 1.916 & 5.649 \\
& 2 & 2 & $2.761(\mathrm{a})$ & .759 & 1.236 & 4.286 \\
& & 1 & $3.167(\mathrm{a})$ & .708 & 1.746 & 4.588 \\
& & 2 & $5.150(\mathrm{a})$ & .779 & 3.585 & 6.714 \\
\hline
\end{tabular}

a Covariates appearing in the model are evaluated at the following values:

Field Independence Score $=10.48$, Spatial Reasoning $=16.66$, Years of Formal Education $=16.35$. 
APPENDIX E-Means for the Total Number of Trials

\begin{tabular}{|c|c|c|c|c|c|c|}
\hline $\begin{array}{l}\text { Age Group of } \\
\text { Subject }\end{array}$ & $\begin{array}{l}\text { Distractor } \\
\text { Auditory }\end{array}$ & $\begin{array}{l}\text { Distractor } \\
\text { Visual }\end{array}$ & Mean & $\begin{array}{l}\text { Std. } \\
\text { Error }\end{array}$ & \multicolumn{2}{|c|}{$\begin{array}{c}\text { 95\% Confidence } \\
\text { Interval }\end{array}$} \\
\hline \multirow{5}{*}{ Age 18-28 } & \multirow{4}{*}{1} & & & & Lower & Upper \\
\hline & & & & & Bound & Bound \\
\hline & & 1 & $5.810(a)$ & 1.002 & 3.798 & 7.822 \\
\hline & & 2 & $6.305(a)$ & 1.027 & 4.242 & 8.368 \\
\hline & \multirow[t]{2}{*}{2} & 1 & $6.059(a)$ & .884 & 4.283 & 7.835 \\
\hline & & 2 & $7.000(a)$ & 1.038 & 4.915 & 9.086 \\
\hline \multirow[t]{4}{*}{ Age 40-50 } & \multirow[t]{2}{*}{1} & 1 & $7.027(a)$ & 1.121 & 4.775 & 9.279 \\
\hline & & 2 & $8.291(a)$ & .994 & 6.294 & 10.288 \\
\hline & \multirow[t]{2}{*}{2} & 1 & 5.686(a) & .847 & 3.986 & 7.387 \\
\hline & & 2 & 4.883(a) & 1.012 & 2.850 & 6.916 \\
\hline \multirow[t]{4}{*}{ Age 51-65 } & \multirow[t]{2}{*}{1} & 1 & $11.047(a)$ & 1.207 & 8.623 & 13.472 \\
\hline & & 2 & $5.850(a)$ & .986 & 3.869 & 7.831 \\
\hline & \multirow[t]{2}{*}{2} & 1 & $6.921(a)$ & .919 & 5.075 & 8.767 \\
\hline & & 2 & $9.073(a)$ & 1.012 & 7.040 & 11.105 \\
\hline
\end{tabular}

a Covariates appearing in the model are evaluated at the following values:

Field Independence Score $=10.48$, Spatial Reasoning $=16.66$, Years of Formal Education $=16.35$. 
APPENDIX F-Means for the Number of Times the Instructional Video was Watched

\begin{tabular}{|c|c|c|c|c|c|c|}
\hline $\begin{array}{l}\text { Age Group of } \\
\text { Subject }\end{array}$ & $\begin{array}{l}\text { Distractor } \\
\text { Auditory }\end{array}$ & $\begin{array}{l}\text { Distractor } \\
\text { Visual }\end{array}$ & Mean & $\begin{array}{l}\text { Std. } \\
\text { Error }\end{array}$ & \multicolumn{2}{|c|}{$\begin{array}{c}\text { 95\% Confidence } \\
\text { Interval }\end{array}$} \\
\hline & & & & & Lower & Upper \\
\hline & & & & & Bound & Bound \\
\hline \multirow[t]{4}{*}{ Age 18-28 } & 1 & 1 & $4.016(a)$ & .822 & 2.365 & 5.668 \\
\hline & & 2 & 4.273(a) & .843 & 2.580 & 5.966 \\
\hline & 2 & 1 & $4.839(a)$ & .726 & 3.381 & 6.297 \\
\hline & & 2 & $5.066(a)$ & .852 & 3.354 & 6.778 \\
\hline \multirow[t]{4}{*}{ Age 40-50 } & 1 & 1 & 5.042(a) & .920 & 3.194 & 6.890 \\
\hline & & 2 & $5.283(a)$ & .816 & 3.644 & 6.923 \\
\hline & 2 & 1 & $4.284(a)$ & .695 & 2.888 & 5.680 \\
\hline & & 2 & $3.584(a)$ & .831 & 1.916 & 5.253 \\
\hline \multirow[t]{4}{*}{ Age 51-65 } & 1 & 1 & $5.641(a)$ & .991 & 3.651 & 7.630 \\
\hline & & 2 & $5.402(a)$ & .809 & 3.776 & 7.028 \\
\hline & 2 & 1 & 4.441(a) & .754 & 2.926 & 5.956 \\
\hline & & 2 & $6.919(a)$ & .831 & 5.251 & 8.587 \\
\hline
\end{tabular}

a Covariates appearing in the model are evaluated at the following values:

Field Independence Score $=10.48$, Spatial Reasoning $=16.66$, Years of Formal Education $=16.35$. 


\section{APPENDIX G-Means for Trial Time}

\begin{tabular}{|c|c|c|c|c|c|c|}
\hline \multirow[t]{3}{*}{$\begin{array}{l}\text { Age Group of } \\
\text { Subject }\end{array}$} & \multirow[t]{3}{*}{$\begin{array}{l}\text { Distractor } \\
\text { Auditory }\end{array}$} & \multirow[t]{3}{*}{$\begin{array}{l}\text { Distractor } \\
\text { Visual }\end{array}$} & \multirow[t]{3}{*}{ Mean } & \multirow[t]{3}{*}{$\begin{array}{l}\text { Std. } \\
\text { Error }\end{array}$} & \multicolumn{2}{|c|}{$\begin{array}{c}\text { 95\% Confidence } \\
\text { Interval }\end{array}$} \\
\hline & & & & & Lower & Upper \\
\hline & & & & & Bound & Bound \\
\hline \multirow[t]{4}{*}{ Age 18-28 } & 1 & 1 & $26.084(a)$ & 2.547 & 20.968 & 31.200 \\
\hline & & 2 & $22.216(\mathrm{a})$ & 2.611 & 16.972 & 27.460 \\
\hline & 2 & 1 & 27.848(a) & 2.248 & 23.332 & 32.364 \\
\hline & & 2 & 27.150 (a) & 2.640 & 21.848 & 32.452 \\
\hline \multirow[t]{4}{*}{ Age 40-50 } & 1 & 1 & 34.029 (a) & 2.850 & 28.304 & 39.753 \\
\hline & & 2 & $23.275(a)$ & 2.528 & 18.197 & 28.352 \\
\hline & 2 & 1 & $29.786(a)$ & 2.153 & 25.463 & 34.110 \\
\hline & & 2 & 23.535(a) & 2.573 & 18.368 & 28.703 \\
\hline \multirow[t]{4}{*}{ Age 51-65 } & 1 & 1 & 23.587(a) & 3.068 & 17.424 & 29.750 \\
\hline & & 2 & $29.176(a)$ & 2.507 & 24.140 & 34.212 \\
\hline & 2 & 1 & 26.771(a) & 2.337 & 22.078 & 31.465 \\
\hline & & 2 & $36.006(a)$ & 2.573 & 30.839 & 41.174 \\
\hline
\end{tabular}

a Covariates appearing in the model are evaluated at the following values:

Field Independence Score $=10.48$, Spatial Reasoning = 16.66, Years of Formal Education = 16.35; time is in sec. 
CURRICULUM VITAE

\section{Diana J. Schwerha}

Doctoral Candidate

Department of Industrial and Management Systems Engineering

West Virginia University

Morgantown, WV 26506-6070

Home Address: 861 Pleasant Hills Drive

Washington, PA 15301

Home Phone: 724-228-2144

Work Phone: 304-293-4607 ext. 3723

Home Email: dschwerha@dp.net

Work Email: djschwerha@mail.wvu.edu

\section{EDUCATION}

West Virginia University, Morgantown, WV

Doctor of Philosophy in Industrial and Management Systems Engineering

Expected Graduation Date: Spring 2004

Interests: The Aging Worker, Optimization of Job Performance, Macroergonomics, Workstation Design, Applied

Anthropometry

West Virginia University, Morgantown, WV

Center on Aging

Graduate Certificate in Gerontology, 2002

West Virginia University, Morgantown, WV

Master of Science in Occupational Hygiene and Occupational Safety

December 1996

University of Pittsburgh, Pittsburgh, PA

Master of Arts in Fine Arts

May 1993

Duquesne University, Pittsburgh, PA

Master of Arts in History

May 1991

Mary Washington College, Fredericksburg, VA

Bachelor of Science in Chemistry

May 1989 


\section{WORK EXPERIENCE}

\section{National Institute for Occupational Safety and Health}

\section{Morgantown, West Virginia}

Exposure Assessment Branch/ Health Effects Laboratory Division

Research Industrial Hygienist, September 1997 to September 1999

- Project Officer for Project 7144-Direct-on-Filter Analysis of Crystalline Silica Using Photoacoustic FTIR; responsibilities include writing budget, writing protocols, designing experiments, writing sole-source requisitions, conducting research, maintaining all records, purchasing all equipment related to project, writing and presenting data gathered from project

- Contributed to the project to develop a silica monitor for field use; responsibilities included conducting research, purchasing necessary equipment, and maintaining records

\section{National Institute for Occupational Safety and Health}

Morgantown, West Virginia

Environmental Investigations Branch/ Division of Respiratory Disease Studies

Visiting Fellow, November 1996 to August 1997

- Conducted a case-control study on the early development of CWP in miners

- Worked on a project with IUOE to screen for silicosis in Chicago area employees

- Worked on database hazard surveillance; used SAS and NIOSH databases

\section{National Institute for Occupational Safety and Health}

Morgantown, West Virginia

Environmental Investigations Branch/ Division of Respiratory Disease Studies

Engineering Technician, May through September 1996

- Conducted experiments using Fourier Transform Infrared Spectroscopy

- Worked on an exposure assessment study of coal miners

\section{Allegheny Ludlum Steel Corporation}

\section{Pittsburgh, Pennsylvania}

Safety Intern, Summer 1995

- Conducted confined space monitoring; calibrated necessary pumps

- Prepared analyzes of total cost for various types of injuries throughout the plants

- Attended to routine safety/ergonomic problems; participated in union-corporate meetings

\section{ENGINEERING COURSES TAUGHT:}

IMSE 314-Advanced Analysis of Engineering Data

Spring 2003

West Virginia University

Department of Industrial and Management Systems Engineering

Morgantown, WV 26506-6070

IMSE 493E--Special Topics Course-Ergonomics and the Aging Worker

Fall 2001

West Virginia University

Department of Industrial and Management Systems Engineering

Morgantown, WV 26506-6070 
IMSE 277-Engineering Economy

Summer 2000

West Virginia University

Department of Industrial and Management Systems Engineering

Morgantown, WV 26506-6070

\section{GRANTS}

November 2000. Received a grant from NIOSH (through Johns Hopkins University) to conduct the pilot study, Work Methods and Compensatory Measures for Older Workers in Physically Demanding Jobs. Amount, \$9,100.00

\section{HONORS/CREDENTIALS}

Member of Alpha Pi Mu

Member Phi Kappa Phi

Currently Graduate Assistant for Dr. Steven Wiker (2002)

NSF Fellowship for Doctoral Work (funded 2000-2001)

Received Fellowship from NIOSH for the academic year 1999-2000

Recipient of a NIOSH service award for work on the NIOSH Silica Prevention Initiative, 1998

Trained Facilitator, 1998

Recipient of an American Industrial Hygiene Association Student Award, Fall 1996

Recipient of NIOSH Grants, 1995-1996

Clinically Certified to use the Current Perception Threshold Neurometer

\section{PROFESSIONAL MEMBERSHIPS}

Member, Human Factors and Ergonomics Society

Member, Institute for Industrial Engineers

\section{THESIS}

Schwerha, D. (1996). Objective Evaluations of Different Training Methods for VDT Work, Unpublished Masters thesis, West Virginia University.

\section{COMPUTER}

SPSS, SAS, Microsoft Excel, Microsoft Word, WordPerfect, Minitab

\section{INVITED PAPERS}

D. J. Schwerha and D. L. McMullin: Prioritizing Ergonomic Research in Aging for the $21^{\text {st }}$ Century American Workforce. International Journal of Experimental Aging Research, Vol. 28, pp. 99-110, 2002.

\section{PAPERS}

D.J. Schwerha, C.S. Orr, B.T. Chen, and S.C. Soderholm: Direct-on-filter Analysis of Crystalline Silica Using Photoacoustic Fourier Transform-infrared Spectroscopy. Analytica Chimica Acta. Vol. 457, pp. 257-264, 2002. 
P. Gao, B.T. Chen, F.J. Hearl, M.A. McCawley, D.J. Schwerha, W. Chen, J-Q Chen, and S.C. Soderholm: Estimating Respirable Mass Concentrations from Historical Total Dust Measurements for Chinese Iron/Copper, Tin and Tungsten Miners, and Pottery Workers. Annals of Occupational Hygiene. Vol. 44(4), pp. 251-257, 2000.

P. Gao, B.T. Chen, J-Q. Chen, W. Chen, Z. Zhuang, F.J. Frank, D.J. Schwerha, M.A. McCawley, and S.C. Soderholm: Two Approaches to Converting Historical Mining Dust Exposures into Respirable Fraction Based on the Microscope Sizing Measurements. Chinese Journal of Industrial Hygiene and Occupational Diseases. Vol. 17(3), 1999.

\section{POSTERS/CONFERENCE PRESENTATIONS}

D.J. Schwerha: Current Research on the Relationship Between Ergonomics, Quality, and the Older Worker. Given as a presentation at the American Industrial Hygiene Conference and Exhibition, June 1-6, 2002 in San Diego, CA.

D.J. Schwerha: The Effects of Age and Noise on Psychophysical Ratings in Cognitive and Physical Tasks. Given as a presentation at the IIE Doctoral Colloquium, May 18-19, 2002 in Orlando, FL.

D.J. Schwerha, D.L. McMullin, and M. Jaraiedi: Work Methods and Compensatory Measures for Older Workers in Physically Demanding Jobs: A Pilot Study. Given as a poster presentation at the Johns Hopkins University Student Research Symposium, November 12, 2001 in Baltimore, MD.

D.J. Schwerha: The Effect of Some Worker-Related Variables on Work Ability, Work Technique, and Number of Errors in a Packing Job. Given as a presentation at the Human Factors and Ergonomics Society Conference, October 8-12, 2001 in Minneapolis, MN.

D.J. Schwerha: Boomers Aging in 90's Suburbs: Implications for Home Modification in the Next Few Decades. Oral presentation given at the 2001 West Virginia Conference on Aging, Oct. 4-5, 2001 in Morgantown, WV.

D.J. Schwerha, D.L. McMullin, and M. Jaraiedi: The Interaction of Age and Work Technique on Work Ability and Quality Measures in a Packing Job. To be given as a poster presentation at PREMUS - $4^{\text {th }}$ International Scientific Conference on Prevention of Work-Related Musculoskeletal Disorders, September 30 to October 4, 2001 in the Netherlands (accepted but not presented).

D.J. Schwerha and J. Finstein: Getting the Money that You Need: Tips on Successful Grant Writing. Oral presentation given at the West Virginia Science Teachers Association Annual Meeting, September 20-22, 2001 in Pipestem, WV.

D.J. Schwerha, M. Ferber, and C. Ellison: Encounter Earth Presentation. A poster presentation given as part of a Educational Share-a-thon at the West Virginia Science Teachers Association Annual Meeting, September 20-22, 2001 in Pipestem, WV.

D.J. Schwerha and D.L. McMullin: Prioritizing Ergonomic Research in Aging for the $21^{\text {st }}$ Century American Workforce. Given as an oral presentation at the IEA 2000/HFES 2000 Congress, July 30-August 4, 2000 in San Diego, CA.

D. J. Schwerha, C.S. Orr, B. T. Chen, and S.C. Soderholm: Direct-on-Filter Analysis of Crystalline Silica Using Photoacoustic FTIR Spectroscopy. Presented at the $50^{\text {th }}$ Anniversary of the Pittsburgh Conference on Analytical Chemistry and Applied Spectroscopy, March 7-12, 1999 in Orlando, Florida. 
P. Gao, B.T. Chen, F.J. Hearl, D.J. Schwerha, Z. Zhuang, W. Chen, J-Q Chen, and S.C. Soderholm: Methodological Approaches to Converting Historical Mining Dust Concentrations Based on Microscopic Sizing into Respirable Mass Fraction. Presented at the Sixth Chinese Medical Conference of Labor Health \& Occupational Disease, Dalian, China, May 11-14, 1998.

P. Gao, B. Chen, F. Hearl, D. Schwerha, Z. Zhuang, S. Soderholm, W. Chen, and J. Chen. Comparison of Three Methods to Convert Chinese Mining Dust Exposure into Respirable Fraction. Presented at the American Industrial Hygiene Conference and Exposition, May 9-15, 1998 in Atlanta, GA.

Z. Zhuang, D. Schwerha, B. Chen, G. Feather, and S. Soderholm. Photoacoustic FTIR Spectroscopy for Crystalline Silica Analysis. Presented at the American Industrial Hygiene Conference and Exposition, May 9-15, 1998 in Atlanta, GA.

D. Schwerha, D. McMullin, and L. Frederick. Objective Evaluations of Different Training Methods for VDT Work. Presented at the Human Factors and Ergonomics Society $40^{\text {th }}$ Annual Meeting, September 1996 in Philadelphia, PA.

\section{COMMITTEE MEMBERSHIPS}

National Occupational Exposure Survey II, HELD Representative, 1999 (Delon Hull, Chair)

Derm Interest Group (DIG), 1998, 1999

Derm Policy Working Group, 1998, 1999 